\title{
First report on the anuran fauna of Hai Ha forest, Quang Ninh Province, Vietnam
}

\author{
Cuong The Pham ${ }^{1}$, Quyen Hanh $\mathrm{Do}^{2}$, Hai Ngoc Ngo ${ }^{3,4,5}$, Tung Thanh Tran ${ }^{6}$, Thomas Ziegler ${ }^{4,5}$, \\ Truong Quang Nguyen ${ }^{1,7}$
}

\begin{abstract}
1 Institute of Ecology and Biological Resources, Vietnam Academy of Science and Technology, 18 Hoang Quoc Viet Road, Hanoi 10072, Vietnam. 2 Faculty of Environmental Sciences, University of Science, Vietnam National University, Hanoi 334 Nguyen Trai Road, Hanoi 11400, Vietnam. 3 Vietnam National Museum of Nature, Vietnam Academy of Science and Technology, 18 Hoang Quoc Viet Road, Hanoi 10072, Vietnam. 4 Cologne Zoo, Riehler Strasse 173, D-50735 Cologne, Germany. 5 Institute of Zoology, University of Cologne, Zülpicher Street 47b, D-50674 Cologne, Germany. 6Vinh Phuc College of Education, Trung Nhi Street, Phuc Yen, Vinh Phuc Province 15900, Vietnam. 7 Graduate University of Science and Technology, Vietnam Academy of Science and Technology, 18 Hoang Quoc Viet Road, Hanoi 10072, Vietnam.
\end{abstract}

Corresponding author: Truong Quang Nguyen, nqt2@yahoo.com

\begin{abstract}
Two field surveys were conducted in the Hai Ha forest, Quang Ninh Province, northeastern Vietnam in 2015 and 2016. Based on mophological examinations, we provide the first list of 27 anuran species from this area. Ten species are recorded for the first time from Quang Ninh Province. The anuran fauna of Hai Ha District also contains one species listed in the IUCN Red List as Vulnerable, two species listed in the Red Data Book of Vietnam as Endangered, and two other species endemic to Vietnam (Limnonectes quangninhensis and Quasipaa acanthophora).
\end{abstract}

\section{Keywords}

Anurans, morphology, new records, taxonomy, Hai Ha forest, notheastern Vietnam.

Academic editor: Abhijeet Bayani | Received 12 March 2020 | Accepted 4 August 2020 | Published 20 August 2020

Citation: Pham CT, Do QH, Ngo HN, Tran TT, Ziegler T, Nguyen TQ (2020) First report on the anuran fauna of Hai Ha forest, Quang Ninh Province, Vietnam. Check List 16 (4): 1025-1041. https://doi.org/10.15560/16.4.1025

\section{Introduction}

Recent herpetological research has determined a very high biodiversity of reptiles and amphibians in the border areas between Vietnam and China (Pham et al. 2016, 2017b). A series of new species and new country records have been recently discovered in the region, e.g. Oligodon nagao David, Nguyen, Nguyen, Jiang, Chen, Teynié \& Ziegler, 2012; Gekko adleri Nguyen, Wang, Yang, Lehmann, Le, Ziegler \& Bonkowski, 2013; Bufo gargarizans Cantor, 1842; Odorrana lipuensis Mo, Chen, Wu, Zhang \& Zhou, 2015; Amolops wenshanensis Yuan,
Jin, Li, Stuart \& Wu, 2018; and Lycodon pictus Janssen, Pham, Ngo, Le, Nguyen \& Ziegler, 2019 (David et al. 2012; Nguyen et al. 2013; Pham et al. 2016, 2020; Janssen et al. 2019).

In Hai Ha District of Quang Ninh Province, in the Vietnam side, two new species were recently described, viz. Limnonectes quangninhensis Pham, Le, Nguyen, Ziegler, Wu \& Nguyen, 2017 and Opisthotropis haihaensis Ziegler, Pham, Nguyen, Nguyen, Wang, Wang, Stuart, \& Le, 2019 (Pham et al. 2017b; Ziegler et al. 
2019). These new discoveries from Quang Ninh Province underline the significantly underestimated biodiversity of northeastern Vietnam. Based on the results of our recent field surveys in the period between 2015 and 2016, we herein provide the first list of amphibians recorded from Hai Ha forest, Hai Ha District, Quang Ninh Province.

\section{Methods}

Field surveys were conducted in the Hai Ha forest, Hai Ha District, Quang Ninh Province (Fig. 1) in June 2015 by Pham CT, Ngo HN and in May 2016 by Pham CT, Nguyen TV. Hai Ha District contains more than 15,000 ha of natural forest (https://haiha.quangninh.gov.vn).

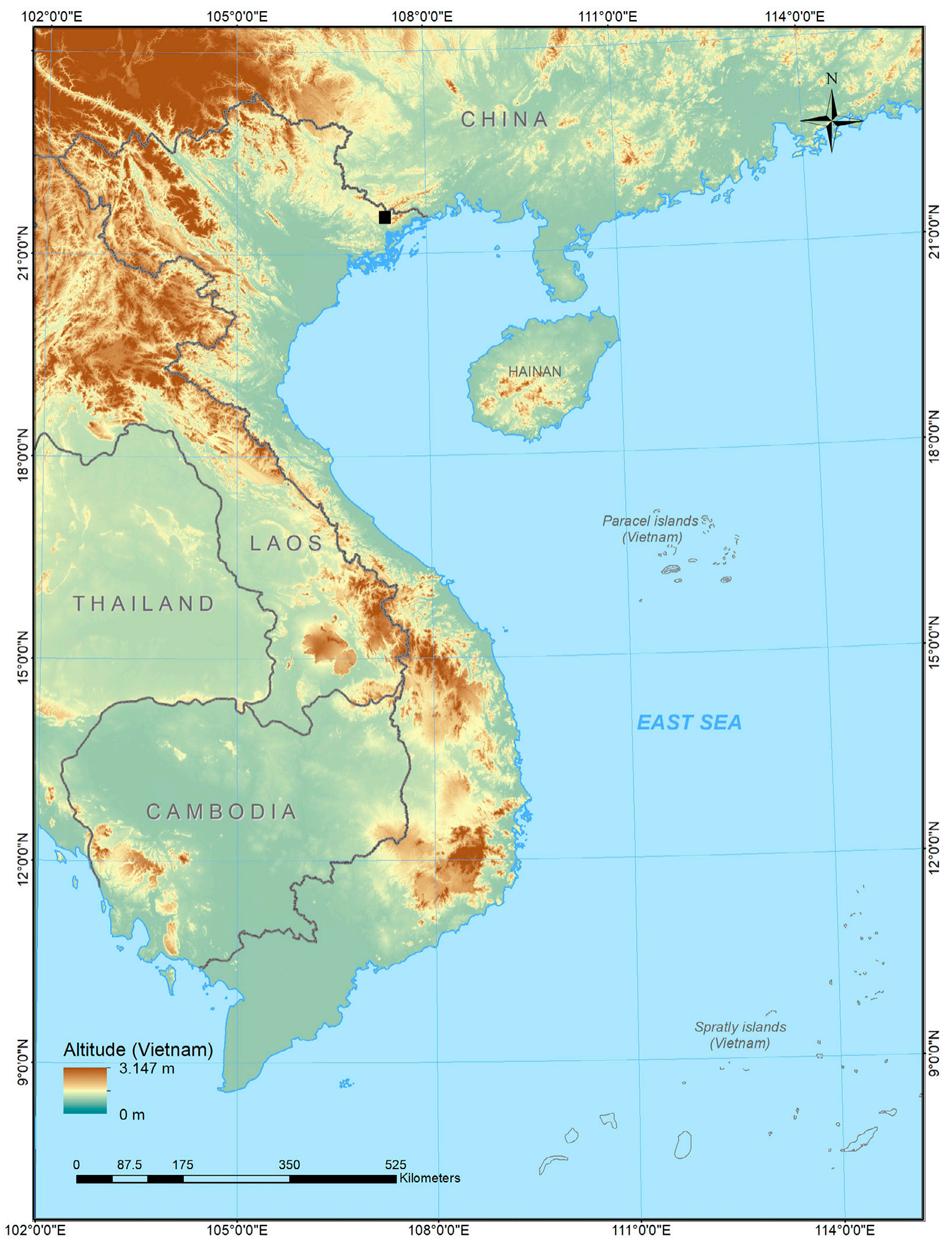

Figure 1. Map showing the sampling site in Hai Ha District (black square), Quang Ninh Province, northeastern Vietnam. 
The main habitat type was secondary forests of medium and small hardwoods mixed with shrubs and vines at elevations between 100 and $900 \mathrm{~m}$ above sea level (a.s.l.) (Fig. 2).

Survey transects were set up along eight streams and three forest paths, approximately $1,000-1,200 \mathrm{~m}$ in length. We also surveyed four small ponds in the forest for searching amphibian specimens. After photographing individuals in life, specimens were euthanized in a closed vessel with a piece of cotton wool containing ethyl acetate (Simmons 2002), fixed in $80 \%$ ethanol for five hours, and then transferred to $70 \%$ ethanol for permanent storage. Specimens referred to in this paper are deposited in the collection of the Institute of Ecology and Biological Resources (IEBR), Hanoi, Vietnam.

Taxonomic identification was based on examination of specimens and data obtained from the literature, for example Bourret (1942), Taylor (1962), Inger et al. (1999), Ziegler (2002), Ohler (2003), Bain et al. (2003, 2009), Bain and Nguyen (2004a, 2004b), Dubois and Ohler (2009), Fei et al. (2009, 2010), Ohler et al. (2011), Hecht et al. (2013), Hou et al. (2017), Yuan et al. (2018), and $\mathrm{Yu}$ et al. (2019). Measurements were taken with digital calipers to the nearest $0.1 \mathrm{~mm}$ (Wabeco, Germany). Abbreviations are as follows: $\mathrm{ED}=$ horizontal eye diameter (eye length), $\mathrm{EN}=$ distance between anterior corner of eye and nostril, $\mathrm{HL}=$ head length, HW = head width, IND = internarial distance, IOD = interorbital distance, $\mathrm{NS}=$ distance between nostril and tip of snout, $\mathrm{SL}=$ snout length, SVL = snout-vent length (from tip of snout to cloaca), TYD = maximum tympanum diameter, TED $=$ distance between anterior margin of tympanum and posterior corner of eye, UEW = width of upper eyelid. Sex was determined by the presence of internal vocal sac opening or gonadal inspection. For webbing formula, we followed Glaw and Vences (2007).

\section{Results}

Bufonidae Gray, 1825

\section{Duttaphrynus melanostictus (Schneider, 1799)}

Figure 3A

Materials examined. VIETNAM • 1 o, 1 q; Quang Ninh Province, Hai Ha District, Quang Son Commune; $21^{\circ} 32.120^{\prime} \mathrm{N}, 107^{\circ} 39.418^{\prime} \mathrm{E}$; alt.154 m; 5 May 2016; Pham CT and Nguyen TV leg.; collected on the ground of forest paths; IEBR 4613, 4614

Identification. Size large (male SVL $45.8 \mathrm{~mm}$, female SVL $93.4 \mathrm{~mm}$ ); head wider than long (HL 14.6-31.6 $\mathrm{mm}$, HW 16.2-39.3 mm); snout truncate; parotoid glands prominent, elongate; tympanum distinct, round (TYD 2.3-6.4 mm); vomerine teeth absent; tongue round posteriorly. Fingers free of webbing, toes with basal webbing, webbing formula: I2-2 $\frac{1}{2} \mathrm{II}_{1} \frac{1}{2}-3 \mathrm{III} 2-3 \mathrm{IV} 3-2 \mathrm{~V}$; tibio-tarsal articulation reaching up to the tympanum. Skin: dorsum and upper surface of limbs with conical, spiny warts; warts smaller on flanks, venter finely granular.

Coloration in life: upper head and dorsum yellowish

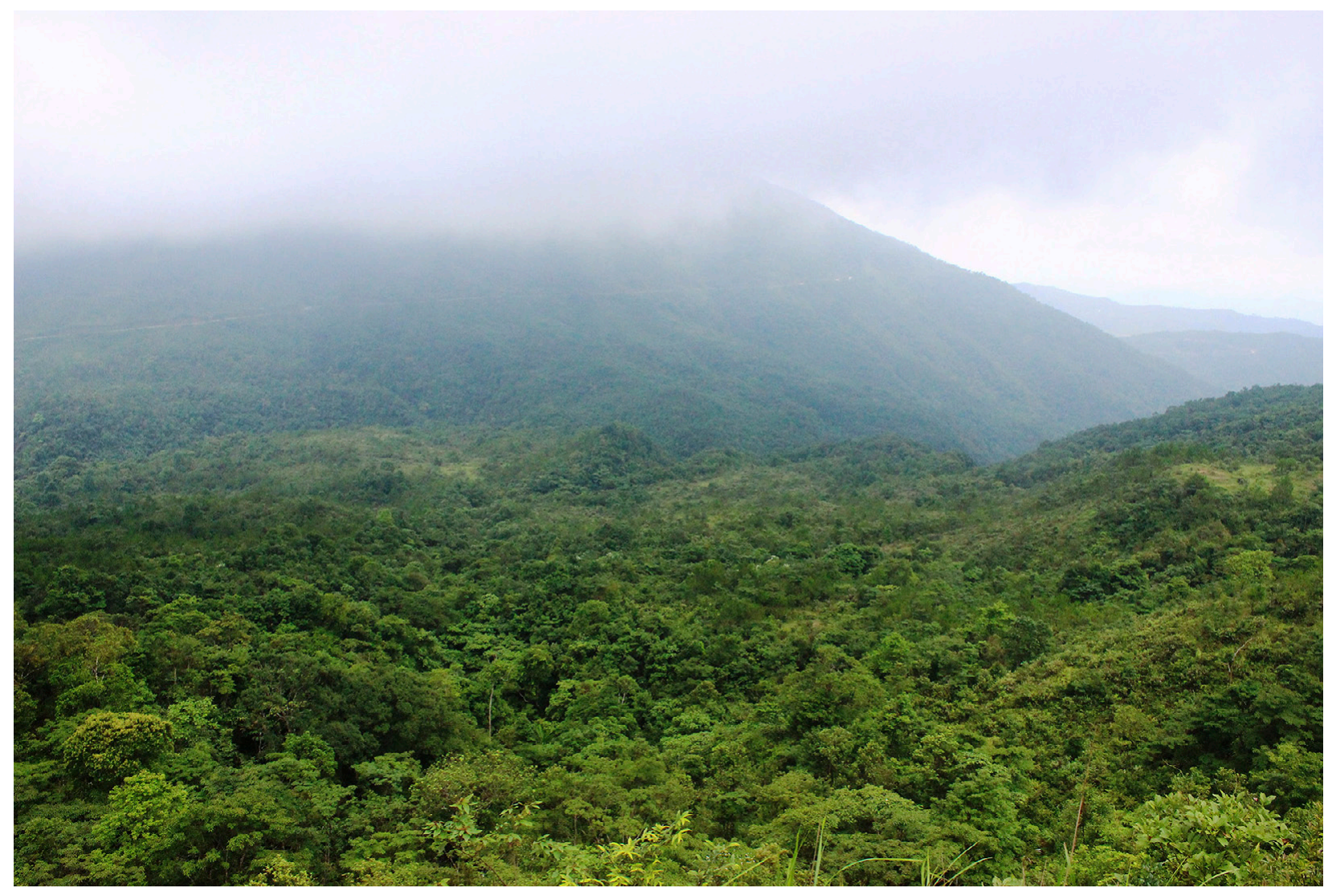

Figure 2. Evergreen forest of Hai Ha District in Quang Ninh Province, Vietnam. Photograph C.T. Pham 


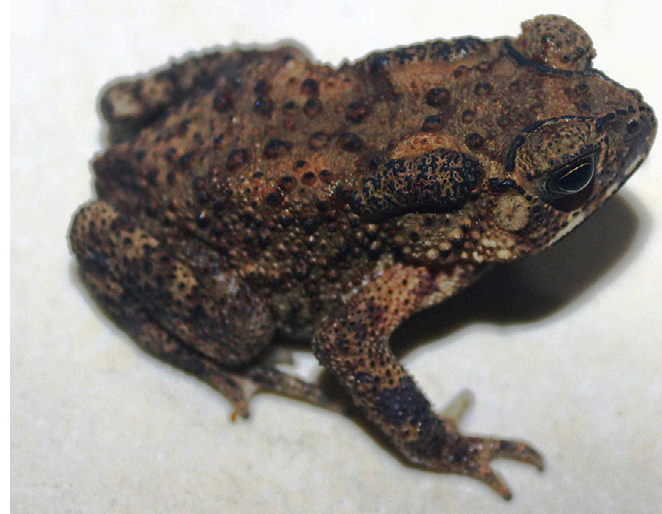

A
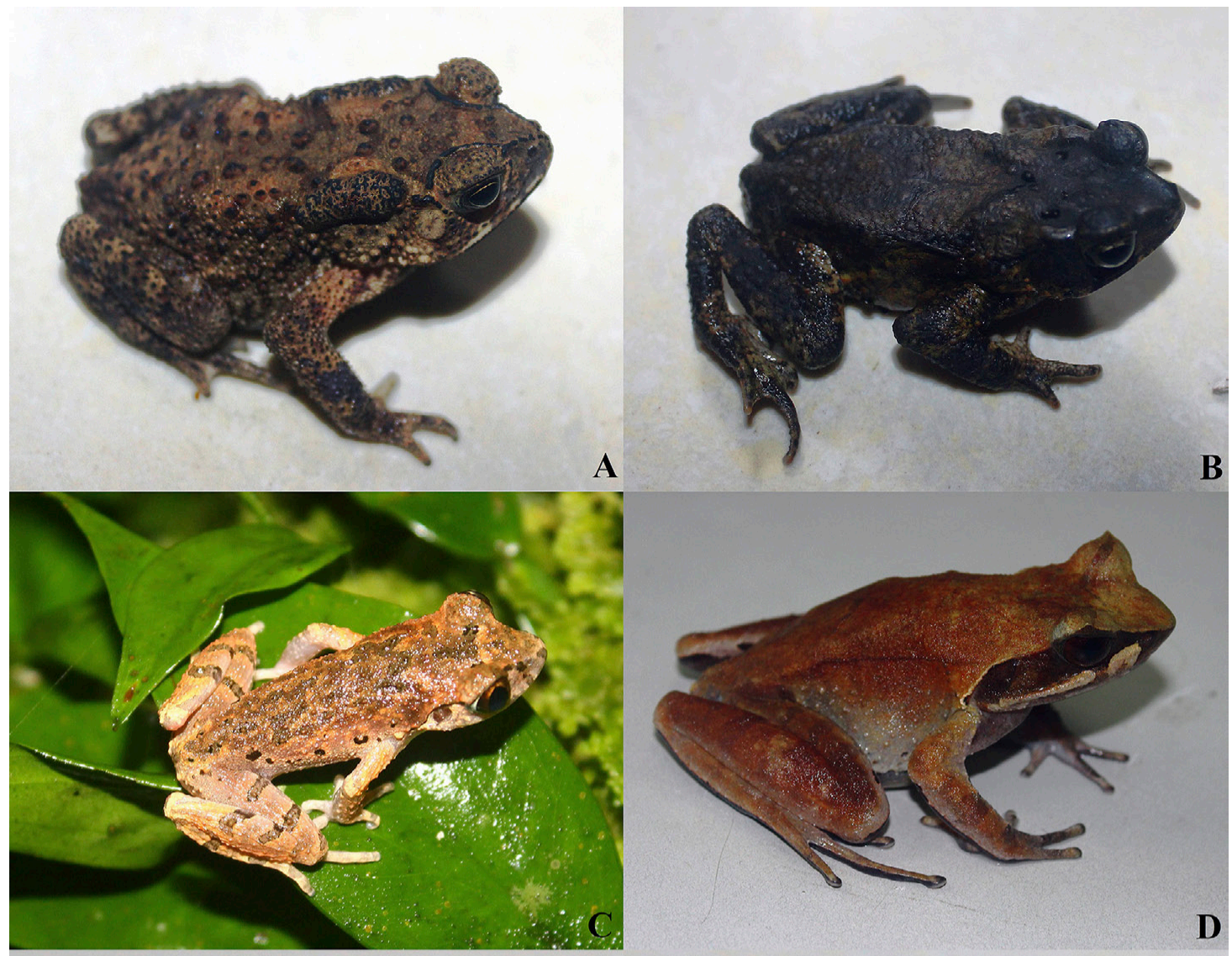

D
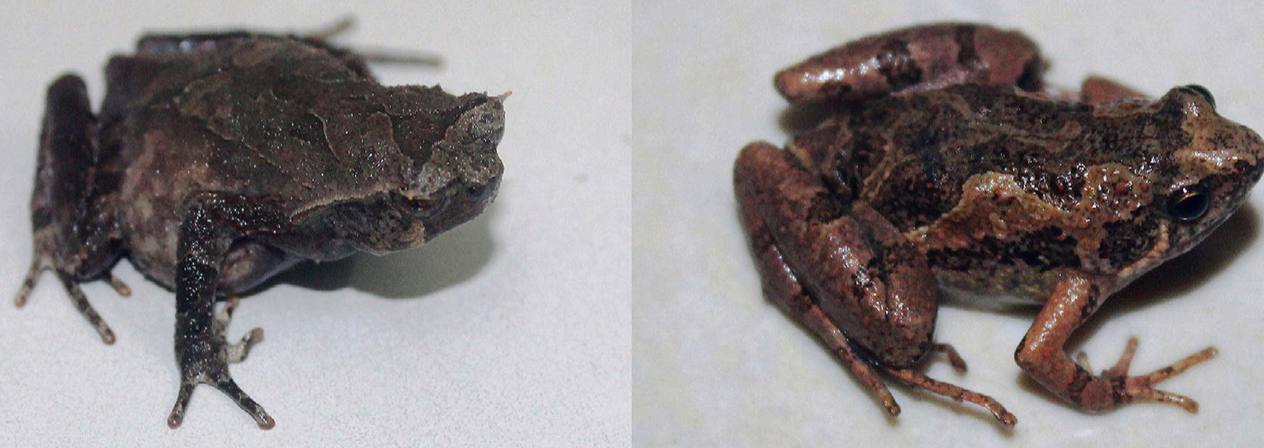

$\mathbf{E}$
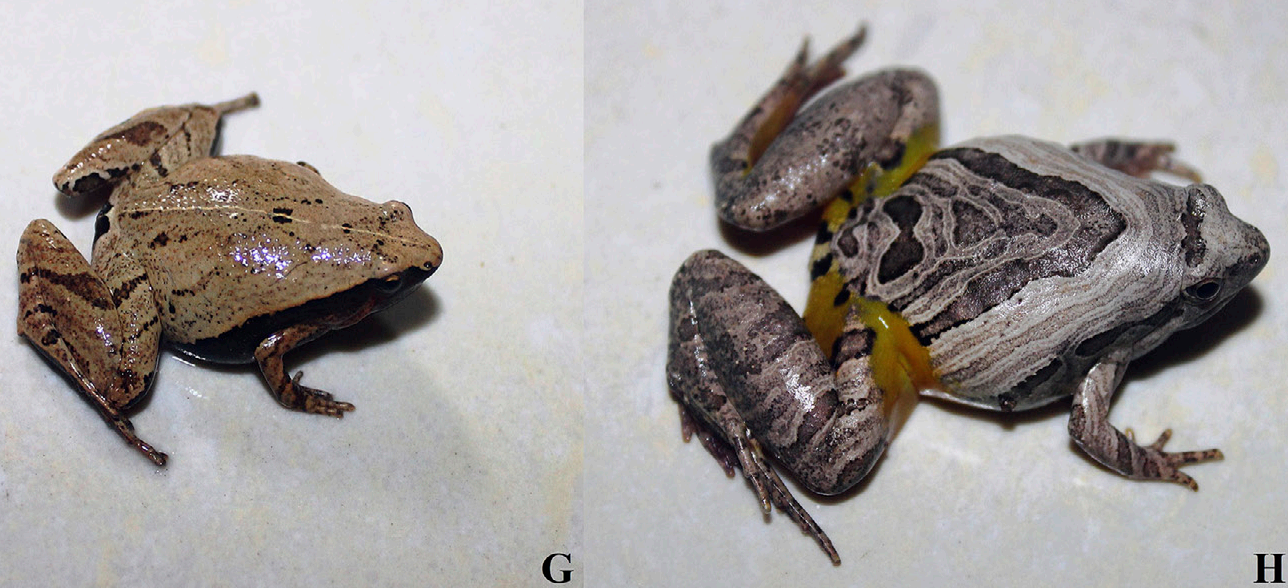

Figure 3. Bufonidae (A, B), Megophryidae (C-E), and Microhylidae (F-H) of Hai Ha forest, Quang Ninh Province, Vietnam. A. Duttaphrynus melanostictus (IEBR 4613). B. Ingerophrynus galeatus (IEBR 4616). C. Leptobrachella minima (IEBR 4620). D. Megophrys maosonensis (IEBR 4628). E. Megophrys microstoma (IEBR 4630). F. Microhyla butleri (IEBR 4632). G. Microhyla heymonsi (IEBR 4634). H. Microhyla pulchra (IEBR 4637). Photographs C.T. Pham. 
grey to dark brown with black spines; venter cream; tip of fingers and toes black; tip of warts black (Bourret 1942; Ziegler 2002).

Distribution. This is a common species in Vietnam (Nguyen et al. 2009). Elsewhere, the species has been known from Sri Lanka and India eastwards to Malaysia and the Philippines (Frost 2020).

\section{Ingerophrynus galeatus (Günther, 1864)}

Figure 3B

Materials examined. VIETNAM • $1 \hat{\jmath}, 1$ q; Quang Ninh Province, Hai Ha District, Quang Son Commune; $21^{\circ} 36.208^{\prime} \mathrm{N}, 107^{\circ} 41.298^{\prime} \mathrm{E}$; alt. $425 \mathrm{~m}$; 9 May 2016; Pham CT and Nguyen TV leg.; collected on the ground near a small stream; IEBR 4615, 4616.

Identification. Size large (male SVL $54.8 \mathrm{~mm}$, female SVL $71.2 \mathrm{~mm}$ ); head wider than long (HL 14.6-31.6 mm, HW 16.2-39.3 mm); snout truncate; nostril closer to tip of snout than to eye (NS 1.5-1.9 mm, EN 3.7-5.1 mm); vomerine teeth absent; tongue elongate, round posteriorly; a well-developed bone crest beyond eye above tympanum, reaching oval parotoid gland; tympanum distinct, smaller than eye length (TYD 3.9-4.4 mm, ED 4.4-5.7 mm). Fingers free of webbing; toes with rudimentary webbing; tibio-tarsal articulation reaching to the eye. Skin: dorsum with warts; flanks with tubercles; venter granular.

Coloration in life: dorsum grey with reddish warts and brown to dark grey marbling; limbs with dark brown bars, venter pale yellowish grey with some black markings (Bourret 1942; Ziegler 2002; Hecht et al. 2013).

Distribution. In Vietnam, this species has been reported from northern Vietnam to Dong Nai Province (Nguyen et al. 2009). This is the first record of I. galeatus from Quang Ninh Province. Elsewhere, the species has been known from China (Hainan), Laos, and Cambodia (Frost 2020).

Megophryidae Bonaparte, 1850

\section{Leptobrachella minima (Taylor, 1962)}

Figure 3C

Materials examined. VIETNAM • $11 \hat{\jmath}$; Quang Ninh Province, Hai Ha District, Quang Son Commune; $21^{\circ}$ $35.865^{\prime} \mathrm{N}, 107^{\circ} 40.159^{\prime} \mathrm{E}$; alt. $768 \mathrm{~m}$; 7-10 May 2016; Pham CT and Nguyen TV leg.; collected on the rock in small streams; IEBR 4617-4627.

Identification. Size small (males SVL 28.8-35.2 mm); head longer than wide (HL 10.6-12.7 mm, HW 10.2$12.6 \mathrm{~mm}$ ); snout slightly pointed; nostril closer to tip of snout than to eye (EN 1.6-2.4 mm, NS 2.4-3.6 mm); tympanum round, distinct (TYD 1.4-2.1 mm); vomerine teeth absent; tongue oval, notched posteriorly. Fingers without dermal fringe, free of webbing; tips of fingers round, slightly swollen; tips of toes slightly swollen; webbing formula I2-2 $\frac{1}{2} \mathrm{II} 2-3 \mathrm{III} 2 \frac{1}{2}-4 \mathrm{IV} 4-2^{1 / 2} \mathrm{~V}$; tibiotarsal articulation reaching to the eye. Skin: dorsal surface of head smooth; dorsum, flanks and upper part of limbs granular; supratympanic fold present, from posterior edge of eye to axilla; venter smooth.

Coloration in life: dorsal surface light brown or reddish brown; flanks cream with some black spots; dorsal limbs light brown with dark crossbars; venter irregular brown with cream markings (Ohler et al. 2011).

Distribution. In Vietnam, this species has been reported from Dien Bien, Son La, Hoa Binh, and Thanh Hoa provinces (Frost 2020). This is the first record of L. minima from Quang Ninh Province. Elsewhere, the species has been reported from Thailand and Laos (Frost 2020).

\section{Megophrys maosonensis Bourret, 1937 \\ Figure 3D}

Materials examined. VIETNAM • 2 \%; Quang Ninh Province, Hai Ha District, Quang Son Commune; $21^{\circ}$ $34.370^{\prime} \mathrm{N}, 107^{\circ} 38.421^{\prime} \mathrm{E}$; alt. $395 \mathrm{~m}$; 10 May 2016; Pham CT and Nguyen TV leg.; collected on the rock of waterfall; IEBR 4628, 4629.

Identification. Size large (females SVL 88.0-89.3 mm); head longer than wide (HL 31.4-32.3 mm, HW 31.0$32.3 \mathrm{~mm}$ ); snout round; nostril further to tip of snout than to eye (EN 5.1-5.9 mm, NS 5.7-6.4 mm); tympanum round, distinct (TYD $5.1 \mathrm{~mm}$ ); vomerine teeth present; tongue round, nicked behind. Fingers without dermal fringe, free of webbing; tips of fingers round; tips of toes round; webbing formula I2-21/2II $2-3 \frac{1}{2}$ III $3-$ 4IV4-2 $\frac{1}{2} \mathrm{~V}$; tibio-tarsal articulation reaching to the eye. Skin: dorsal surface and upper of limbs smooth, flanks granular; supratympanic fold present; venter smooth.

Coloration in life: dorsal surface light brown; flanks cream; dorsal limbs light brown with black crossbars; venter cream with brown pattern and white spots (Bourret 1942).

Distribution. In Vietnam, this species has been reported from Lao Cai, Cao Bang, and Vinh Phuc provinces (Frost 2020). This is the first record of M. maosonensis from Quang Ninh Province. Elsewhere, the species has been reported from China (Frost 2020).

\section{Megophrys microstoma (Boulenger, 1903)}

Figure 3E

Materials examined. VIETNAM • 2 ๙ึ; Quang Ninh Province, Hai Ha District, Quang Son Commune; $21^{\circ}$ $36.026^{\prime} \mathrm{N}, 107^{\circ} 42.252^{\prime} \mathrm{E}$; alt. $330 \mathrm{~m}$; 9 May 2016; Pham CT and Nguyen TV leg.; collected on leaves near rocky streams; IEBR 4630, 4631.

Identification. Size small (males SVL 29.5-33.0 mm); head shorter than wide (HL 8.3-9.4 mm, HW 8.4-9.5 $\mathrm{mm}$ ); snout truncate, protruding; nostril closer to tip of snout than to eye (EN 1.5-1.7 mm, NS $0.9 \mathrm{~mm}$ ); tympanum distinct (TYD 2.0-2.5 $\mathrm{mm}$ ); vomerine teeth absent. Fingers without dermal fringe, free of webbing; tips of fingers round, not enlarged into discs; subarticular tubercles absent; palmar tubercles indistinct; tips of toes round; webbing rudimentary; subarticular tubercles absent; metatarsal tubercle indistinct; tibio-tarsal 
articulation reaching to the eye. Skin: dorsal surface shagreened with symmetric glandular ridges; flanks shagreened with scattered granules; venter smooth.

Coloration in life: dorsum reddish brown, upper surface of limbs with dark brown transverse bars; a white bar present below the eye; flanks with some small black spots; venter cream with brown marbling (Ohler 2003).

Distribution. In Vietnam, this species has been reported from Lao Cai and Ha Giang provinces in the north, southwards to Dak Lak and Lam Dong provinces. Elsewhere, the species is known from China, Laos, Thailand, and Cambodia (Nguyen et al. 2009; Frost 2020).

Microhylidae Günther, 1858

\section{Microhyla butleri Boulenger, 1900 Figure 3F}

Materials examined. VIETNAM $\bullet 1 \hat{\rho}, 1$; ; Quang Ninh Province, Hai Ha District, Quang Son Commune; $21^{\circ}$ $30.757^{\prime} \mathrm{N}, 107^{\circ} 39.544^{\prime} \mathrm{E}$; alt. 75 m; 4 May 2016; Pham CT and Nguyen TV leg.; collected on forest paths near a small stream; IEBR 4632, 4633.

Identification. Size small (male SVL $23.7 \mathrm{~mm}$, female SVL $28.4 \mathrm{~mm}$ ); head longer than wide (HL 6.6$8.2 \mathrm{~mm}$, HW 6.1-7.9 mm); snout pointed, snout length greater than eye diameter (SL 1.8-2.0 mm, ED 3.3-3.6 $\mathrm{mm}$ ); nostril closer to tip of snout than to eye (NS 1.5$1.6 \mathrm{~mm}$, EN 1.7-2.1 mm); tympanum hidden; vomerine teeth absent; tongue round posteriorly; male with visible vocal sacs. Fingers free of webbing, toes with webbing at base, webbing formula: I2-21/2II1 $1 \frac{1}{2}-3 \mathrm{III} 2^{1} / 2-4 \mathrm{IV} 4-2 \mathrm{~V}$; tibio-tarsal articulation reaching to the eye. Skin: dorsum, flanks, dorsal surface of limbs smooth with small tubercles; venter smooth.

Coloration in life: dorsal surface of head and body grey with brownish and reddish markings; one whitish stripe from eye to the base of fore limb; limbs with brown transverse bars; throat and chest mottled with dark brown; venter cream (Hecht et al. 2013; Pham et al. 2017a).

Distribution. This is a widespread species in Vietnam, except for the Mekong Delta (Nguyen et al. 2009). Elsewhere, the species is known from China, northeastern India, Myanmar, Thailand, Malaysia, and Singapore (Frost 2020).

\section{Microhyla heymonsi Vogt, 1911}

Figure $3 \mathrm{G}$

Material examined. VIETNAM • 1 ; Quang Ninh Province, Hai Ha District, Quang Son Commune; $21^{\circ}$ $31.254^{\prime} \mathrm{N}, 107^{\circ} 40.523^{\prime} \mathrm{E}$; alt. $97 \mathrm{~m}$; 8 May 2016; Pham CT and Nguyen TV leg.; collected on forest path; IEBR 4634.

Identification. Size small (female SVL $26.2 \mathrm{~mm}$ ); body flattened, triangle shaped; head longer than wide (HL 7.3 $\mathrm{mm}$, HW $7.2 \mathrm{~mm}$ ); snout pointed; longer than eye (SL $2.9 \mathrm{~mm}$, ED $1.5 \mathrm{~mm}$ ); nostrils closer to tip of snout than to eye (NS $1.4 \mathrm{~mm}$, EN $1.7 \mathrm{~mm}$ ); tympanum concealed; vomerine teeth absent; tongue large, round posteriorly. Fingers free of webbing, tips of fingers widened into small discs; toes with webbing at base, webbing formula I2-21/2II2-3III3-4IV4-3V; tibio-tarsal articulation reaching to anterior edge of eye. Skin: dorsum and venter smooth, supratympanic fold indistinct.

Coloration in life: uniform light brown above; with a thin, white vertebral line extending from tip of snout to vent; one small black spot in middle of back; head and body with a black lateral band extending from tip of snout to near groin; venter white (Bourret 1942; Ziegler 2002; Bain and Nguyen 2004a).

Distribution. This is a widespread species in Vietnam (Nguyen et al. 2009). Elsewhere, the species is known from India, China, Laos, Thailand, Cambodia, Malaysia, and Indonesia (Nguyen et al. 2009; Frost 2020).

\section{Microhyla pulchra (Hallowell, 1861) \\ Figure $3 \mathrm{H}$}

Materials examined. VIETNAM • 2 ภ, 1 †; Quang Ninh Province, Hai Ha District, Quang Son Commune; $21^{\circ} 31.420^{\prime} \mathrm{N}, 107^{\circ} 38.949^{\prime} \mathrm{E}$; alt. $144 \mathrm{~m} ; 7$ May 2016; Pham CT and Nguyen TV leg.; collected from the banks of a small stream and on forest paths; IEBR 4635-4637.

Identification. Size small (males SVL 29.9-34.3 mm, female SVL $37.4 \mathrm{~mm}$ ); body flattened, triangular shaped; head slightly wider than long (HL 8.2-10 mm, HW 9.4$10.1 \mathrm{~mm}$ ); snout pointed; tympanum invisible; vomerine teeth absent; tongue short, round posteriorly; males with vocal sacs. Fingers free of webbing, tips of fingers not enlarged; toes webbed, webbing formula I1-2II1$3 \mathrm{III} 2^{1} \frac{1}{2}-3^{1} / 2 \mathrm{IV} 4-2 \mathrm{~V}$; tibio-tarsal articulation reaching between eye and tip of snout. Skin: dorsum and venter smooth; a distinct fold present between posterior edges of the eyes; cloacal region granular.

Coloration in life: dorsum brown with a dark brown, $\mathrm{V}$-shaped marking, containing brown and white alternating bands; dark brown transversal band from posterior corner of the eye towards upper flanks; groin and anterior part of thigh yellow; limbs with transverse bars; venter whitish yellow; throat and chest speckled with grey (Bourret 1942; Ziegler 2002; Bain and Nguyen 2004a).

Distribution. This is a common species in Vietnam (Frost 2020). Elsewhere, this species in known from northeastern India to southern China, Cambodia, Guam, Indochina, and Thailand (Frost 2020).

Dicroglossidae Anderson, 1871

\section{Fejervarya limnocharis (Gravenhost, 1829) \\ Figure 4A}

Materials examined. VIETNAM • 2 ô; Quang Ninh Province, Hai Ha District, Quang Son Commune; $21^{\circ}$ $31.420^{\prime} \mathrm{N}, 107^{\circ} 38.949^{\prime} \mathrm{E}$; alt. $144 \mathrm{~m}$; 7 May 2016; Pham $\mathrm{CT}$ and Nguyen TV leg.; collected on forest paths; IEBR 4638,4639 .

Identification. Size medium (males SVL 43.5-46.7 mm); head longer than wide (HL 15.4-16.7 mm; HW 13.6-16.7 

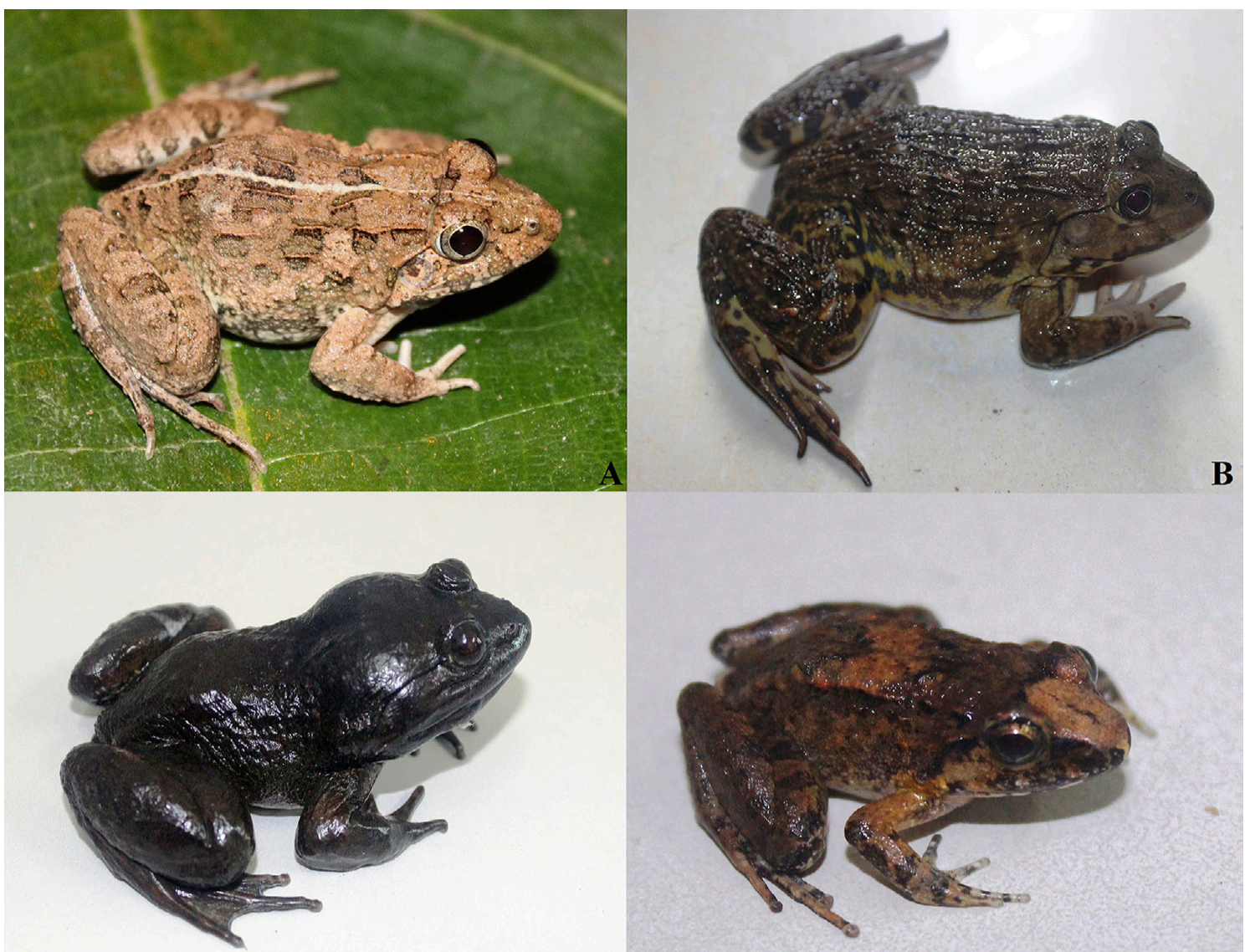

C

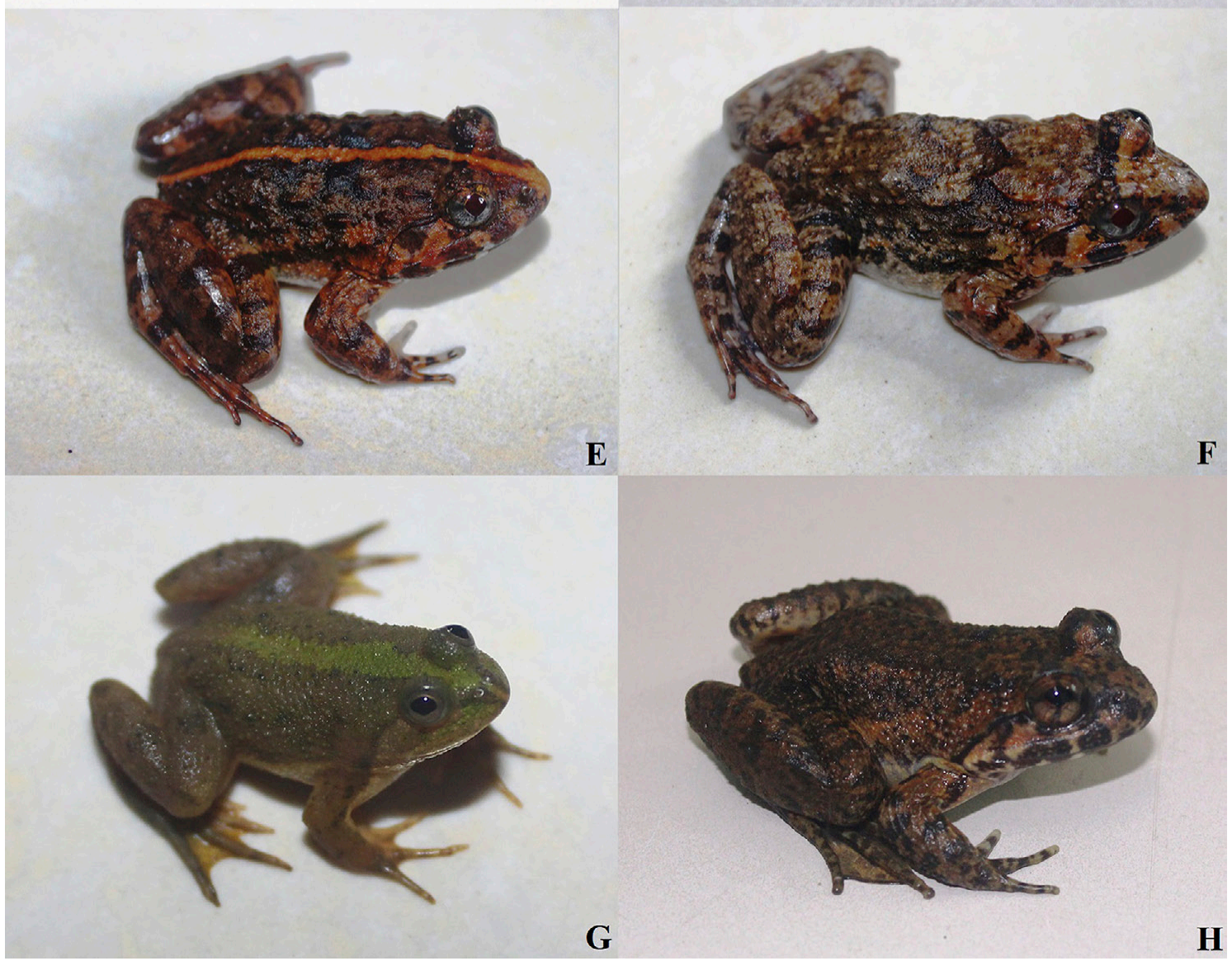

Figure 4. Dicroglossidae of Hai Ha forest, Quang Ninh Province, Vietnam. A. Fejervarya limnocharis (IEBR 4638). B. Hoplobatrachus rugulosus (IEBR 4640). C. Limnonectes bannaensis (IEBR 4645). D. Limnonectes limborgi (IEBR 4532). E. Limnonectes quangninhensis (male) (IEBR 3912). F. Limnonectes quangninhensis (female) (IEBR 3915). G. Occidozyga lima (IEBR 4647). H. Quasipaa acanthophora (IEBR 4648). Photographs C.T. Pham. 
$\mathrm{mm}$ ); snout pointed, longer than eye (SL 6.7-7.4 mm, ED 4.1-4.9 mm); nostrils closer to tip of snout than to eye (NS 2.9-3.2 mm, EN 3.6-4.1 mm); tympanum distinct (TYD 2.8-3.3 mm); vomerine teeth present; tongue bifid; male with vocal sacs. Fingers free of webbing, tips of fingers blunt, not expanded; toes webbed, webbing formula I1-2II1-2 $\frac{1}{3}$ III $2-3 I V 2-1 \frac{1}{2} \mathrm{~V}$; tibio-tarsal articulation reaching to the eye. Skin: dorsum granular with several irregular dermal folds; supratympanic fold distinct; venter smooth; males with a nuptial pad on finger I.

Coloration in life: dorsal surface of head and body greyish green with some mottled brown; a white vertebral stripe from tip of snout to before vent present or absent; lips with dark vertical bars; limbs with transverse bars or spots; venter cream (Bourret 1942; Taylor 1962; Ziegler 2002).

Distribution. In Vietnam, this species has been reported from the entire country (Nguyen et al. 2009). Elsewhere, this species is known from China, Myanmar, Laos, Cambodia, Thailand, Malaysia, and Indonesia (Frost 2020).

\section{Hoplobatrachus rugulosus (Wiegmann, 1834) Figure 4B}

Material examined. VIETNAM • 1 ơ; Quang Ninh Province, Hai Ha District, Quang Son Commune; $21^{\circ}$ $30.673^{\prime} \mathrm{N}, 107^{\circ} 39.452^{\prime} \mathrm{E}$; alt. $156 \mathrm{~m}$; 4 May 2016; Pham CT and Nguyen TV leg.; collected from the bank of a small stream; IEBR 4640.

Identification. Size large (male SVL $102.9 \mathrm{~mm}$ ); head broader than long (HW $38.1 \mathrm{~mm}$, HL $34.7 \mathrm{~mm}$ ); snout oval in dorsal view; tympanum round, smaller than eye diameter (TYD $5.8 \mathrm{~mm}$, ED $9.1 \mathrm{~mm}$ ); vomerine teeth present; tongue bifid. Arms short; fingers without webbing; tips of fingers obtusely pointed; hind limbs short; toes fully webbed, tips of toes pointed, without discs; tibio-tarsal articulation reaching to the eye. Skin: dorsum granular with irregular rows of elongate dermal ridges; flanks and upper surface of limbs with tubercles; venter smooth; supratympanic fold distinct.

Coloration in life: dorsum light brown with black blotches; chest surface whitish with black blotches; venter cream (Bourret 1942; Taylor 1962; Ziegler 2002).

Distribution. In Vietnam, this species has been reported from the entire country (Nguyen et al. 2009). Elsewhere, this species is known from China, Taiwan, Myanmar, Laos, Thailand, Cambodia, and Malaysia (Nguyen et al. 2009).

\section{Limnonectes bannaensis Ye, Fei \& Jiang, 2007 Figure 4C}

Materials examined. VIETNAM • $5 \hat{\sigma}, 1$; ; Quang Ninh Province, Hai Ha District, Quang Son Commune; $21^{\circ}$ $34.198^{\prime} \mathrm{N}, 107^{\circ} 38.404^{\prime} \mathrm{E}$; alt. 460 m; 11 May 2016; Pham CT and Nguyen TV leg.; collected from the banks or on the rock of a small stream; IEBR 4641-4646.

Identification. Size large (males SVL 61.2-90.6 mm, female SVL $66.5 \mathrm{~mm}$ ); head large, flattened, wider than long (HL 28.8-40 mm, HW 26.0-39.3 mm); snout round, longer than eye diameter (SL 8.9-12.6 mm, ED 7.7-11.7 $\mathrm{mm}$ ); canthus rostralis indistinct; loreal region oblique and slightly concave; nostril closer to tip of snout than to eye (EN 4.3-5.9 mm, NS 4.3-6.7 mm); tympanum invisible; vomerine teeth present; tongue bifurcated posteriorly; lower jaw with two tooth-like processes; males without vocal sacs. Arms short, fingers free of webbing, tips of fingers obtuse or slightly swollen; subarticular tubercles on fingers and toes large; hind limbs short; toes short, fully webbed; tips of toes dilated into small discs; subarticular tubercles large; inner metatarsal tubercle large, outer metatarsal tubercle absent; tibio-tarsal articulation reaching to the eye. Skin: dorsally and ventrally smooth; small and homogenous tubercles on the leg and foot; supratympanic fold present.

Coloration in life: dorsum reddish brown to greyish brown, mostly with dark mottling or marbling; sometimes with light vertebral stripe; lower region of flanks lighter; limbs with dark transversal bands; venter cream, ventral side of limbs darker; throat, pectoral region, belly and outer edges of limbs with dark mottles (Ye et al. 2007; McLeod et al. 2015; Pham et al. 2019).

Distribution. In Vietnam, this species is known from Ha Giang and Cao Bang provinces in the north, southwards to Thua Thien Hue Province (Pham et al. 2018). Elsewhere, this species is known from China, Myanmar, and Laos (Frost 2020).

\section{Limnonectes limborgi (Sclater, 1892) \\ Figure 4D}

Material examined. VIETNAM • 1 đ̧; Quang Ninh Province, Hai Ha District, Quang Son Commune; $21^{\circ}$ $34.230^{\prime} \mathrm{N}, 107^{\circ} 38.482^{\prime} \mathrm{E}$; alt. $450 \mathrm{~m}$; 10 May 2016; Pham CT and Nguyen TV leg.; collected on the ground near a small stream; IEBR 4532.

Identification. Size small (male SVL $28.5 \mathrm{~mm}$ ); head longer than wide (HL $11.8 \mathrm{~mm}$, HW $11.2 \mathrm{~mm}$ ); snout slightly pointed anteriorly in dorsal view; snout length greater than eye diameter (SL $4.4 \mathrm{~mm}$, ED $3.6 \mathrm{~mm}$ ); tympanum visible, round, approximately $50 \%$ of eye diameter; vomerine teeth in two oblique ridges; tongue cordiforn, deeply notched posteriorly; arms short and thin; fingers free of webbing; tips of fingers blunt, not expanded into discs. Tibia and thigh short; tips of toes blunt, not expanded into discs; webbing formula I1-2II1 $1 / 2-2 \frac{1}{2}$ III $2-$ $3 \mathrm{IV} 3 \frac{1}{2}-1 \frac{1}{2} \mathrm{~V}$; tibio-tarsal articulation reaching between eye and tip of snout. Skin: dorsal surface of head and body smooth with small tubercles; supratympanic fold distinct; dorsolateral folds present; venter smooth.

Coloration in life: dorsal surface light brown or light yellow with small dark spots; a black cross bar between the eyes and an inverted V shaped marking between the shoulders; thighs and tibia with dark brown cross bars; venter cream; throat cream with black pattern (Bourret 1942; Inger and Stuart 2010).

Distribution. In Vietnam, this species has been reported from Lao Cai Province in the north, southwards to Dong Nai and Kien Giang provinces (Nguyen et al. 
2009; 2019). Elsewhere, the species has been reported from Laos, Cambodia, Thailand, and Myanmar (Inger and Stuart 2010; Frost 2020).

\section{Limnonectes quangninhensis Pham, Le, Nguyen, Ziegler, Wu \& Nguyen, 2017 \\ Figure 4E, F}

Materials examined. VIETNAM • $1 \hat{\jmath}, 2$ क; Quang Ninh Province, Hai Ha District, Quang Son Commune; $21^{\circ} 30.751^{\prime} \mathrm{N}, 107^{\circ} 38.550^{\prime} \mathrm{E}$; alt. $119 \mathrm{~m} ; 16$ June 2015; C.T. Pham and H.N. Ngo leg.; collected in the water of rocky streams; IEBR 3907-3909. • 3 ô, 3 o; Quang Ninh Province, Hai Ha District, Quang Son Commune; $21^{\circ} 32.296^{\prime} \mathrm{N}, 107^{\circ} 39.376^{\prime} \mathrm{E}$; alt. $229 \mathrm{~m}$; 7 May 2016; C.T. Pham and Nguyen TV leg.; collected in the water of rocky streams; IEBR 3910-3915.

Identification. Size lager (males SVL 51.1-62.2 mm, females SVL 49.3-62.9 mm); habitus robust with enlarged head; head longer than wide (HL 23.3-31.1 mm, HW 20.1-29.5 mm in males; $20.5-25.8 \mathrm{~mm}, 20.2-23.4 \mathrm{~mm}$ in females); snout round anteriorly in dorsal view; rostral length greater than eye diameter (SL 8.2-11.5 mm, ED 6.8-8.7 $\mathrm{mm}$ in males; $7.6-9.7 \mathrm{~mm}, 6.1-8.7 \mathrm{~mm}$ in females); tympanum distinct, approximately $60 \%$ of eye diameter (TYD 4.0-5.5 $\mathrm{mm}$ in males; $4.1-5.0 \mathrm{~mm}$ in females); vomerine teeth in two oblique ridges; tongue cordiform, deeply notched posteriorly; lower jaw with two tooth-like; external vocal sac absent in males. Arms short; fingers free of webbing; tips of fingers blunt, not expanded into discs; finger I with nuptial pad, composed of minute spines. Tibia longer than thigh; tips of toes blunt, slightly round; webbing well developed, formula I0-0II0-1/3III0-1/3IV1/2-0V; tibio-tarsal articulation reaching between eye and tip of snout. Skin: dorsal surface of head, body and flanks with flattened tubercles; supratympanic fold distinct; dorsal surface of limbs and thighs smooth; dorsal surface of tibia with fine tubercles; throat, chest, belly and ventral surface of thighs smooth.

Coloration in life: head with a narrow light brown bar in interorbital region; dorsum yellowish brown with a light yellow vertebral stripe and a dark brown marking; upper part of flanks yellowish brown, lower part of flanks yellowish white; dorsal surface of fore and hind limbs yellowish brown with black crossbars; throat and chest white with dark brown marking; ventral surface of fore and hind limbs, as well as belly white (Pham et al. 2017b).

Distribution. This species is currently known only from Quang Ninh and Bac Giang provinces, Vietnam (Pham et al. 2017b, 2019).

\section{Occidozyga lima (Gravenhorst, 1829)} Figure 4G

Material examined. VIETNAM • 1 ĥ; Quang Ninh Province, Hai Ha District, Quang Son Commune; $21^{\circ}$ 31.420'N, 107³8.940'E; alt. 144 m; 7 May 2016; Pham CT and Nguyen TV leg.; collected in the water near rice field; IEBR 4647.
Identification. Size small (male SVL $25.3 \mathrm{~mm}$ ); head longer than wide (HL $8.6 \mathrm{~mm}$ HW $8.1 \mathrm{~mm}$ ); snout short, a rather pointed oval; nostril at the midway between eye and tip of snout (EN $1.8 \mathrm{~mm}$, NS $1.6 \mathrm{~mm}$ ); tympanum distinct (TYD $0.9 \mathrm{~mm}$ ); vomerine teeth absent; tongue elongate, pointed posteriorly. Fingers short with elongate pointed digits, webbed at base; toes fully webbed; tibiotarsal articulation reaching to tympanum. Skin: dorsum with small spines and tubercles; supratympanic fold distinct.

Coloration in life: dorsal surface of head and dorsum brownish with a green line from tip of snout to vent; two dark brown lines on chest area; venter and ventral surface of limbs with white spots; (Bourret 1942; Taylor 1962).

Distribution. This is a widespread species in Vietnam (Nguyen et al. 2009). Elsewhere, the species is known from India, Bangladesh, China, Myanmar, Laos, Thailand, Cambodia, Malaysia, and Indonesia (Nguyen et al. 2009).

\section{Quasipaa acanthophora Dubois \& Ohler, 2009}

Figure 4H

Material examined. VIETNAM • 1 §; Quang Ninh Province, Hai Ha District, Quang Son Commune; $21^{\circ}$ $34.370^{\prime} \mathrm{N}, 107^{\circ} 38.421^{\prime} \mathrm{E}$; alt. $395 \mathrm{~m}$; 10 May 2016; Pham CT and Nguyen TV leg.; collected from a rocky stream; IEBR 4648.

Identification. Size large (male SVL $71.8 \mathrm{~mm}$ ); head wider than long (HW $32.2 \mathrm{~mm}$, HL 29.8); snout round, slightly protruding, longer than eye diameter (SL 12.3 $\mathrm{mm}$, ED $8.4 \mathrm{~mm}$ ); canthus rostralis indistinct; loreal region concave; nostrils closer to eyes than to tip of snout (EN $5.1 \mathrm{~mm}$, NS $4.5 \mathrm{~mm}$ ); interorbital distance narrower than internarial distance and upper eyelid (IND $7.1 \mathrm{~mm}$, IOD $5.1 \mathrm{~mm}$, UEW $7.3 \mathrm{~mm}$ ); vomerine teeth present; tongue cordiform, deeply notched posteriorly; tympanum indistinct. Arm short; fingers free of webbing; tips of fingers round, slightly enlarged, without discs; toes short and thin; tips of toes round, distinctly enlarged, without discs; toes fully webbed. Skin: dorsal surface of head, body and limbs shagreened with regularly disposed glandular warts; supratympanic fold distinct; upper part of flanks shagreened with elongated glandular warts, lower part with small tubercles; dorsolateral folds absent; venter smooth.

Colouration in life: dorsal surface light brown, with grey spots; dorsal surface of limbs with black crossbars; supratympanic fold black; lips with vertical bars; venter yellowish white, gular region with black marbling. Male with black nuptial spines present on finger I (Dubois and Ohler 2009).

Distribution. This species is currently known only from Lang Son and Bac Giang provinces, Vietnam (Ohler and Dubois 2009; Hecht et al. 2013; Frost 2020). This is the first record of $Q$. acanthophora from Quang Ninh Province. 
Ranidae Rafinesque, 1814

\section{Amolops ricketti (Boulenger, 1899)}

Figure 5A

Materials examined. VIETNAM • $2 \hat{\jmath}, 3$ \%; Quang Ninh Province, Hai Ha District, Quang Son Commune; $21^{\circ} 31.878^{\prime} \mathrm{N}, 107^{\circ} 38.889^{\prime} \mathrm{E}$; alt. $185 \mathrm{~m}$; 5 May 2016; Pham CT and Nguyen TV leg.; collected on the rock of small streams; IEBR 4649-4653.

Identification. Size medium (males SVL 37.5-41.5 mm, females SVL 52.1-54.6); head longer than broad (HL 14.6-19.4 mm, HW 13.9-18.8 mm); snout round; nostril at the midway between eye and tip of snout (EN 2.6-3.8 $\mathrm{mm}$, NS 2.7-3.6 mm); tympanum round, small, about $1 / 3$ of eye length (TYD 1.4-2.0 mm; ED 3.8-5.6 mm); vomerine teeth present; tongue notched posteriorly; males with vocal sacs. Finger short, free of webbing, with enlarged discs; toes fully webbed, without tarsal fold; intercalary cartilage tubercles absent; toe discs with circummarginal groove, smaller than finger discs; tibio-tarsal articulation reaching to tip of snout. Skin: dorsum flattened granules, venter smooth.

Coloration in life: dorsum greyish brown with light grey streaks; throat and chest with dark grey streaks; venter cream (Bourret 1942; Inger et al. 1999).

Distribution. In Vietnam, this species has been reported from northern to central Vietnam. Elsewhere, the species is known from China (Nguyen et al. 2009).

\section{Amolops wenshanensis Yuan, Jin, Li, Stuart \& Wu, 2018}

\section{Figure 5B}

Material examined. VIETNAM • 1 ô; Quang Ninh Province, Hai Ha District, Quang Son Commune; $21^{\circ}$ 35.635'N, 10740.349'E; alt. 950 m; 9 May 2016; Pham CT and Nguyen TV leg.; collected from a tree, about 1.5 $\mathrm{m}$ above the ground, near a waterfall of a rocky stream; IEBR 4503.

Identification. Body slender, size medium (male SVL $33.2 \mathrm{~mm}$ ); head longer than wide (HL $12.8 \mathrm{~mm}$, HW $12.0 \mathrm{~mm}$ ); snout obtusely round in dorsal view, projecting beyond lower jaw; nostril lateral, closer to the tip of snout than to eye (NS $2.6 \mathrm{~mm}$, EN $3.2 \mathrm{~mm}$ ); canthus rostralis distinct; pupil horizontally oval; loreal region slightly concave and oblique; snout longer than eye diameter (SL $5.6 \mathrm{~mm}$, ED $5.3 \mathrm{~mm}$ ); tympanum distinct, round, smaller than eye diameter (TYD $2.0 \mathrm{~mm}$ ); vomerine teeth present; tongue notched posteriorly; the male with vocal sac openings at corners of mouth; tips of fingers enlarged into round discs with distinct circummarginal grooves; disc of finger III equal to tympanum diameter (fd3/TD 0.95); fingers free of webbing; subarticular tubercle distinct, round, formula 1, 1, 2, 2; male with white nuptial pad on finger I; palmar tubercles distinct; discs of toes smaller than those of fingers; webbing formula: I0-1/3II0-1/2III0-1IV1-0V; tibio-tarsal articulation reaching to the nostril. Skin: dorsal surface of head and body smooth, except granular on posterior part of thigh around vent; supratympanic fold absent; dorsolateral fold present, extending from rear of tympanum to inguinal region; throat, chest, belly and ventral surface of thigh smooth.

Coloration in life: dorsum light green; head side black, with a yellowish stripe on upper lip extending from snout tip to axilla; flanks yellowish brown with green marking; dorsal surface of fore and hind limbs light olive green with irregular, narrow, incomplete greyish brown bands; venter immaculate yellow (Yuan et al. 2018).

Distribution. The species was previously known only from the Wenshan National Nature Reserve, Yunnan Province and Jingxi County, Guangxi Province, China (Yuan et al. 2018). Pham et al. (2020) provided the first record of this species in Quang Ninh Province, Vietnam.

Remarks. The specimen from Vietnam slightly differs from the type series from China by having a smaller size (SVL 33.2 mmvs 35.7-39.9 $\mathrm{mm}$ in males) and the presence of distinct transverse bands on dorsal surfaces of limbs.

\section{Hylarana taipehensis (Van Denburgh, 1909)}

Figure 5C

Material examined. VIETNAM • 1 \%; Quang Ninh Province, Hai Ha District, Quang Son Commune; $21^{\circ}$ $30.668^{\prime} \mathrm{N}, 107^{\circ} 40.346^{\prime} \mathrm{E}$; alt. 95 m; 8 May 2016; Pham CT and Nguyen TV leg.; collected on the ground in a rice field; IEBR 4654.

Identification. Size medium (female SVL $36.9 \mathrm{~mm}$ ); head longer than wide (HL $12.9 \mathrm{~mm}$, HW $10.2 \mathrm{~mm}$ ); snout pointed; nostril closer to tip of snout than to eye (EN $3.5 \mathrm{~mm}$, NS $2.5 \mathrm{~mm}$ ); tympanum distinct, approximately same with eye diameter (TYD $2.6 \mathrm{~mm}$, ED $2.8 \mathrm{~mm}$ ); vomerine teeth present; tongue notched posteriorly. Fingers small, free of webbing, tips of fingers swollen; toes with webbing, webbing formula I2-2II121/2III1-3IV2-1V; tibio-tarsal articulation reaching to tip of snout. Skin: dorsal and ventral surfaces smooth; dorsolateral fold distinct.

Coloration in life: dorsum green, with two stripes from behind the eyes to groins; venter white (Bourret 1942; Inger et al. 1999).

Distribution. This is a widespread species in Vietnam (Nguyen et al. 2009). Elsewhere, the species is known from India and Nepal southwards to Thailand and Cambodia (Nguyen et al. 2009).

\section{Odorrana chloronota (Günther, 1875)}

Figure 5D

Materials examined. VIETNAM • 3 o, 4 q; Quang Ninh Province, Hai Ha District, Quang Son Commune; $21^{\circ} 30.760^{\prime} \mathrm{N}, 107^{\circ} 38.557^{\prime} \mathrm{E}$; alt. $307 \mathrm{~m}$; 7 May 2016; Pham CT and Nguyen TV leg.; from the banks or on the rock of a rocky stream; IEBR 4655-4661.

Identification. Males smaller than females (males SVL 51.5-54.0 mm, females SVL 89.9-99.6 mm); head longer than wide (HL 34.8-36.5 mm, HW 30.3-33.3 mm 

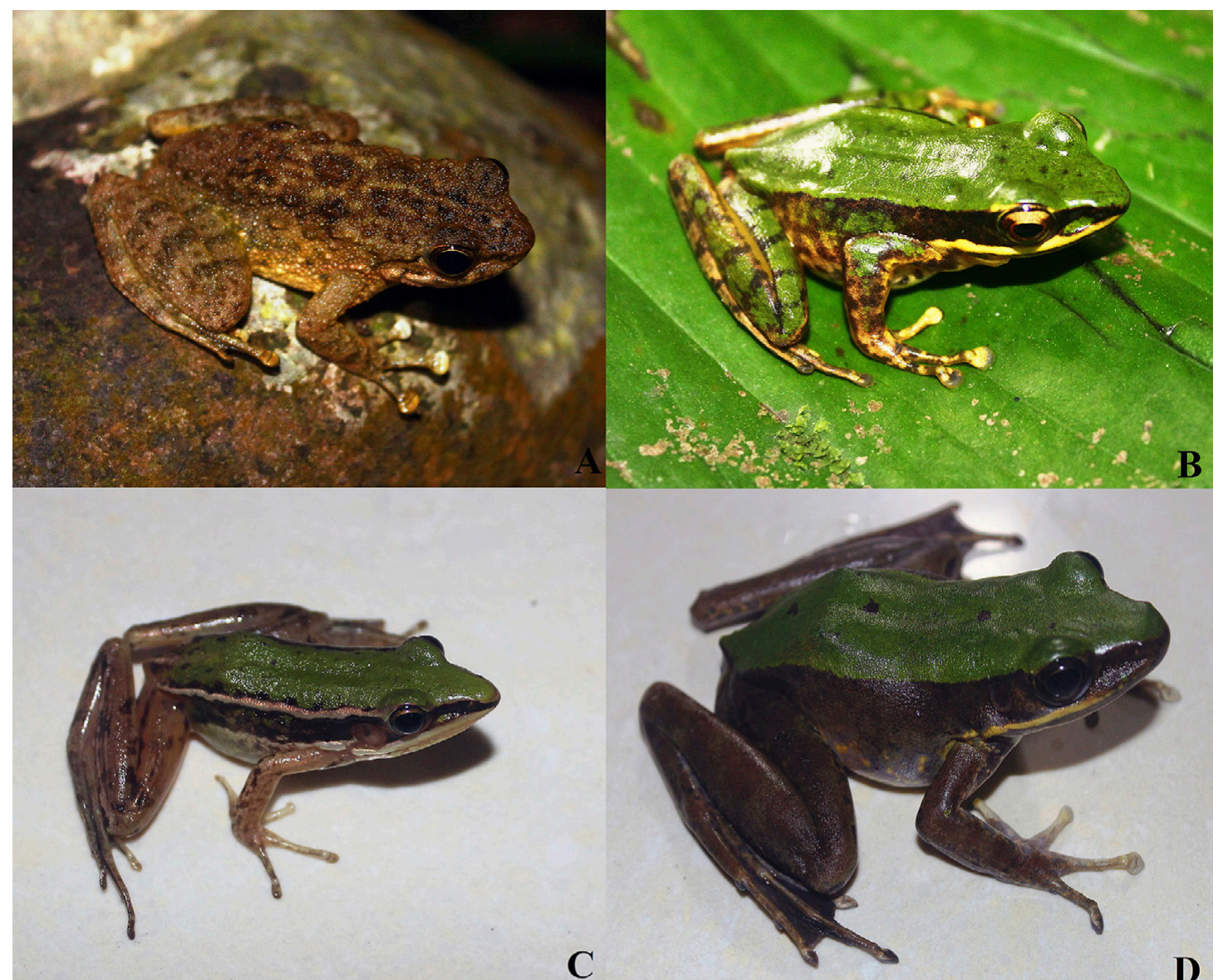

C

D
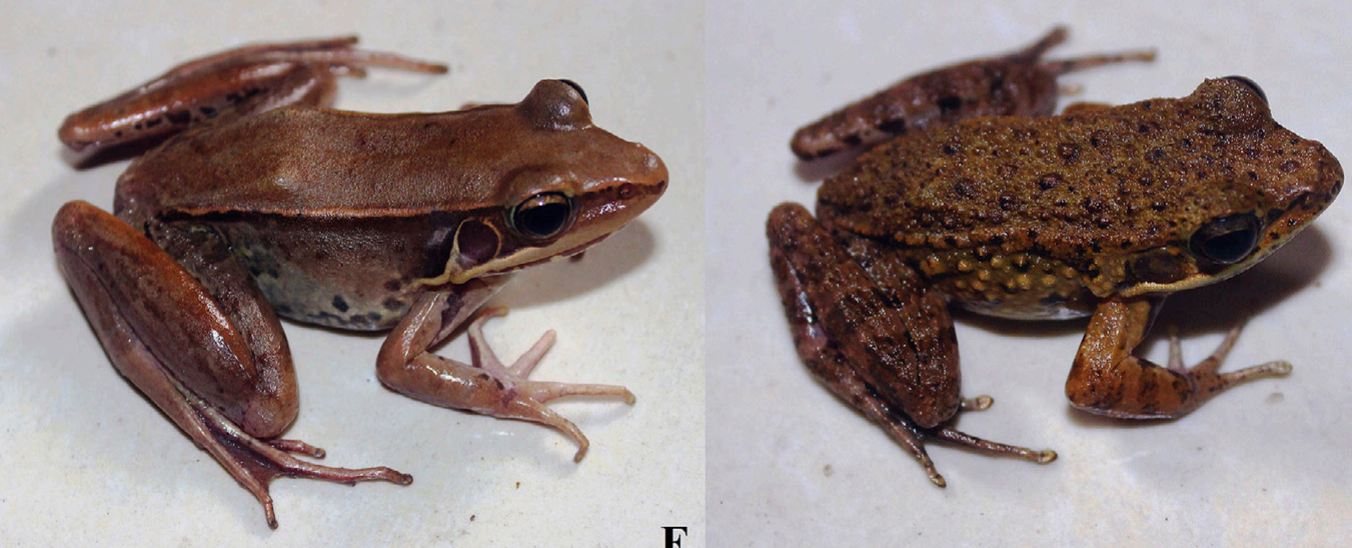

$\mathbf{E}$
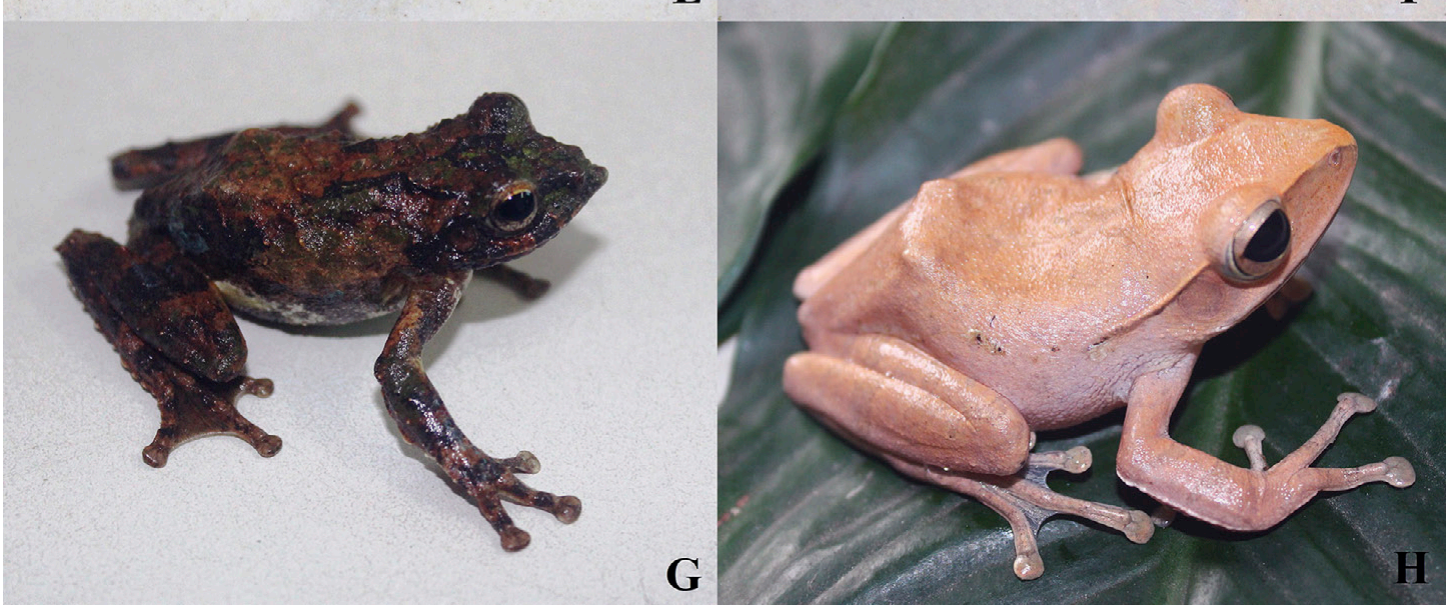

Figure 5. Ranidae (A-F) and Rhacophoridae (G, H) of Hai Ha forest, Quang Ninh Province, Vietnam. A. Amolops ricketti (IEBR 4650). B. Amolops wenshanensis (IEBR 4503). C. Hylarana taipehensis (IEBR 4654). D. Odorrana chloronota (IEBR 4660). E. Sylvirana guentheri (IEBR 4662). F. Sylvirana maosonensis (IEBR 4665). G. Kurixalus cf. hainanus (IEBR 4675). H. Polypedates mutus (IEBR 4681). Photographs C.T. Pham. 
in females, HL 16.2-17.4 mm, HW 19.4-20.3 mm in males); snout round, longer than eye (SL 14.3-15.6 mm, ED 11.5-12.5 mm in females, SL 8.2-8.7 mm, ED 7.5$8.1 \mathrm{~mm}$ in males); pupil round; tympanum distinct, approximately half of eye diameter (TYD 4.9-5.6 mm, ED 11.5-12.5 mm in females, TYD 4.1-5.0 mm, ED 7.5-8.1 $\mathrm{mm}$ in males); vomerine teeth present; tongue cordiform, deeply notched posteriorly; males with vocal sacs. Fingers free of webbing; finger discs larger than those of toes, with circum-marginal groove; toes fully webbed; outer metatarsal tubercle absent; inner metatarsal tubercle elongate; tibio-tarsal articulation reaching beyond tip of snout. Skin: dorsal surface of head and body smooth smooth; flank with small tubercles; supratympanic fold distinct; dorsolateral fold absent; venter smooth.

Coloration in life: dorsum green with or without black spots; lateral side of head and flanks brownish grey; lips white; hind limbs with distinct dark brown bars; webbing dark grey; venter white (Bourret 1942; Bain et al. 2003).

Distribution. In Vietnam, this species has been reported from Bac Kan, Lang Son, Vinh Phuc, and Lam Dong provinces (Nguyen et al. 2009). This is the first record of $O$. chloronota from Quang Ninh Province. Elsewhere, the species has been reported from India, Myanmar to southern China, and southern Vietnam (Frost 2020).

\section{Sylvirana guentheri (Boulenger, 1882)}

Figure 5E

Materials examined. VIETNAM • 2 ô, 1 q; Quang Ninh Province, Hai Ha District, Quang Son Commune; $21^{\circ} 31.254^{\prime} \mathrm{N}, 107^{\circ} 40.523^{\prime} \mathrm{E}$; alt. $97 \mathrm{~m}$; 8 May 2016; Pham CT and Nguyen TV leg.; collected from the banks of small streams; IEBR 4662-4664.

Identification. Size large (males SVL 74.3-84.1 mm, female SVL $78.8 \mathrm{~mm}$ ); head longer than broad (HL 26.819.1mm, HW 23.1-26.7 mm); snout obtusely pointed, strongly projecting beyond mouth opening; nostril closer to tip of snout than to eye (EN 6.6-7.2 mm, NS 4.6-4.9 $\mathrm{mm}$ ); tympanum round, distinct; vomerine teeth present; tongue notched posteriorly; males with vocal sacs. Fingers slender and rather long, without webbing; tips of toes slightly round, webbing formula I1-2II1 $1 \frac{1}{2}-2 \frac{1}{3} \mathrm{III} 1^{1} / 2-$ 3IV3-1V; tibio-tarsal articulation reaching nearby tip of snout. Skin: dorsal and ventral surfaces smooth; dorsolateral fold distinct; supratympanic fold prominent.

Coloration in life: dorsal surface of head and body reddish brown, with dark brown spots; a black line present on either side of head and upper part of flanks, bordering dorsolateral fold below; tympanum dark brown or reddish; limbs with brown crossbars, rear side of thighs yellow with black mottling; throat or chest speckled with brown; venter white or yellow (Bourret 1942; Ziegler 2002).

Distribution. This is a common species in lowland areas of Vietnam (Nguyen et al. 2009). Elsewhere, the species has been reported from China, Taiwan, Myanmar, and Laos (Nguyen et al. 2009; Frost 2020).

\section{Sylvirana maosonensis (Bourret, 1937)}

Figure 5F

Materials examined. VIETNAM • 5 $\lesssim, 3$ o; Quang Ninh Province, Hai Ha District, Quang Son Commune; $21^{\circ} 32.054^{\prime} \mathrm{N}, 107^{\circ} 39.821^{\prime} \mathrm{E}$ and $21^{\circ} 31.760^{\prime} \mathrm{N}, 107^{\circ}$ 38.557'E; alt. $113 \mathrm{~m}$ and $307 \mathrm{~m}$; 5-7 May 2016; Pham CT and Nguyen TV leg.; collected from the banks or on rocks in small streams; IEBR 4665-4672.

Identification. Size medium (males SVL $36.5-43.2 \mathrm{~mm}$, females SVL 48.1-57 mm); head longer than wide (HL 14.5-20 mm, HW 13.1-18.8 mm); snout truncate; nostril closer to tip of snout than to eye (EN 2.9-4.5 mm, NS 2.9-3.5 mm); pupil round; tympanum distinct, smaller than eye length (TYD 2.8-4.4 mm, ED 4.6-5.4 mm); vomerine teeth present; tongue notched posteriorly; males with vocal sacs. Fingers free of webbing, with small discs; discs of toes larger than discs of fingers; toes with webbing, webbing formula I1-2II1-21/2III1-3IV3-1V; tibiotarsal articulation reaching between eye and tip of snout. Skin: dorsal surface of head, body, flanks and thighs with tubercles; dorsolateral fold distinct; supratympanic fold prominent; venter smooth.

Coloration in life: dorsum yellowish brown, flanks lighter with black spots; limbs with dark brown transverse bars; tympanum brown; venter whitish (Bourret 1942; Inger et al. 1999).

Distribution. This species has been reported from northeastern and central Vietnam (Frost 2020). Elsewhere, the species has been reported from China and Laos (Frost 2020).

Rhacophoridae Hoffman, 1932

\section{Kurixalus cf. hainanus (Zhao, Wang \& Shi, 2005) Figure 5G}

Materials examined. VIETNAM • $4 \hat{\sigma}, 1$ q; Quang Ninh Province, Hai Ha District, Quang Son Commune; $21^{\circ} 32.142^{\prime} \mathrm{N}, 107^{\circ} 39.526^{\prime} \mathrm{E}$ and $21^{\circ} 34.230^{\prime} \mathrm{N}, 107^{\circ}$ $38.482^{\prime} \mathrm{E}$; alt. $160 \mathrm{~m}$ and $450 \mathrm{~m}$; 5-10 May 2016; Pham CT and Nguyen TV leg.; collected on tree branches near a water pool, about $0.5-1.5 \mathrm{~m}$ above the ground; IEBR 4673-4677.

Identification. Size medium (males SVL $32.8-34.9 \mathrm{~mm}$, female SVL $44.4 \mathrm{~mm}$ ); Head slightly wider than long (HL 11.3-15.0 mm, HW 11.9-15.4 mm); snout pointed anteriorly, longer than eye (SL 5.1-7.7 mm, ED 3.8-4.3 $\mathrm{mm}$ ); nostril closer to tip of snout than to eye (NS 2.0$3.1 \mathrm{~mm}$, EN 2.5-3.3 mm); tympanum distinct, smaller than eye (TYD 1.9-2.3 mm, ED 3.8-4.3 mm); vomerine teeth in two ridges; males with vocal sacs. Fingers free of webbing, tips of fingers with enlarged discs; toes webbed, webbing formula $\mathrm{I}^{1} / 2-1 \mathrm{II}^{1} / 3-1 \mathrm{III} 1 / 3-1 \mathrm{IV} 1-1 / 3 \mathrm{~V}$; inner metatarsal tubercle small; outer metatarsal tubercle absent; tibio-tarsal articulation reaching between eye and tip of snout. Skin: some scattered flat tubercles on the head, eyelids, and occiput, sparse on dorsum, more dense and larger on flanks, fine granules on rump; chin 
granular, chest nearly smooth; venter and lower part of sides granular.

Coloration in life: dorsal surface of head and body light or reddish brown with green marking, occiput with a dark green marking in triangular shape; tympanum brownish; chin cream with dark spots; throat, chest, venter, and underside of limbs cream (Zhao et al. 2005; Fei et al. 2010).

Distribution. In Vietnam, this species has been reported from northeastern Vietnam (Yu et al. 2017). This is the first record of $K$. cf. hainanus from Quang Ninh Province. Elsewhere, the species has been reported from China (Frost 2020).

Remarks. The specimens from Vietnam slightly differ the type series from China by having a lager head in males (HL 11.9-12.2 $\mathrm{mm}$ vs $9.4-11.8 \mathrm{~mm}$ ) and relative length of fingers $\mathrm{I}<$ II $<$ IV $<$ III (vs I $<$ II $=$ IV $<$ III) (Zhao et al. 2005).

\section{Polypedates mutus (Smith, 1940)}

Figure $5 \mathrm{H}$

Materials examined. VIETNAM • $3 \hat{\jmath}, 1$ q; Quang Ninh Province, Hai Ha District, Quang Son Commune; $21^{\circ} 32.296^{\prime} \mathrm{N}, 107^{\circ} 39.376^{\prime} \mathrm{E}$; alt. 229 m; 7 May 2016; Pham CT and Nguyen TV leg.; collected on tree branches near a water pool, about $1.5-2.5 \mathrm{~m}$ above the ground; IEBR 4678-4681.

Identification. Size large (males SVL 53.8-59.3 mm, female SVL $62.2 \mathrm{~mm}$ ); head longer than wide (HL 19.5$22.4 \mathrm{~mm}$, HW 16.6-21.1 mm); snout pointed, triangular in shape; nostrils closer to tip of snout than to eye (EN 5.8-6.9 mm, NS 1.9-3.5 mm); pupil horizontal; tympanum distinct; smaller than eye diameter (TYD 3.5-4.4 $\mathrm{mm}$, ED 5.1-5.9 mm); vomerine teeth present; tongue notched posteriorly; males with vocal sacs. Fingers free of webbing, tips of fingers expanded into wide discs; tips of toes widened into discs, smaller than those of fingers, webbing formula I2-2II1-2 $\frac{1}{2}$ IIII-3IV2-1V; tibio-tarsal articulation reaching tip of snout. Skin: dorsum with small tubercles, rough; upper surface of limb granular; venter smooth; supratympanic fold present.

Coloration in life: dorsum yellowish brown, with or without dark blotches; a X-shaped pattern present on neck; limbs with dark brown transverse bars; dark brown stripe bordering supratympanic fold from eye beyond arm; flanks bright brown with black blotches; back of thigh with large white spots; belly yellowish white; throat finely mottled or spottet (Ziegler 2002; Ziegler et al. 2006).

Distribution. This is a widespread species in Vietnam (Nguyen et al. 2009). Elsewhere, the species has been reported from China, Myanmar, Laos, Cambodia, and Thailand (Nguyen et al. 2009; Kuraishi et al. 2013; Frost 2020).

\section{Theloderma corticale (Boulenger, 1903)} Figure 6A

Material examined. VIETNAM • 1 \%; Quang Ninh Province, Hai Ha District, Quang Son Commune; $21^{\circ}$ $34.198^{\prime} \mathrm{N}, 107^{\circ} 38.404^{\prime} \mathrm{E}$; alt. 460 m; 10 May 2016; Pham CT and Nguyen TV leg.; collected on leaves next to a forest path; IEBR 4682.

Identification. Size large (female SVL $51.5 \mathrm{~mm}$ ); head wider than long (HL $20.4 \mathrm{~mm}$, HW $21.7 \mathrm{~mm}$ ); snout round, longer than eye diameter (SL $9.1 \mathrm{~mm}$, ED $5 \mathrm{~mm}$ ); nostril closer to tip of snout than to eye (NS $2.8 \mathrm{~mm}$, EN $5.7 \mathrm{~mm}$ ); tympanum small, oval (TYD $3.8 \mathrm{~mm}$ ); vomerine teeth present; tongue notched posteriorly. Fingers free of webbing; tips of fingers and toes enlarged into round discs; toes webbed, webbing formula I0-1/2II0-1III0-1IV1-0V; tibio-tarsal articulation reaching between eye and tip of snout. Skin: dorsal surface of head, body and limbs covered with tubercles or warts of different sizes; ventral skin with small tubercles; supratympanic fold absent.

Coloration in life: dorsal surface of head and body green marbled with reddish brown spots; dark brown bars present on upper surface of fore and hind limbs; flanks yellow with black spots; venter yellow with green (Inger et al. 1999; Orlov et al. 2006; Hou et al. 2017).

Distribution. In Vietnam, this species is known from $\mathrm{Ha}$ Giang and Cao Bang provinces in the north, southwards to Quang Binh Province (Nguyen et al. 2009; Luu et al. 2013). This is the first record of T. corticale from Quang Ninh Province. Elsewhere, the species has been reported from China and Laos (Frost 2020).

\section{Theloderma lateriticum Bain, Nguyen \& Doan 2009 Figure 6B}

Material examined. VIETNAM • 1 ${ }^{\lambda}$; Quang Ninh Province, Hai Ha District, Quang Son Commune; $21^{\circ}$ $34.198^{\prime} \mathrm{N}, 107^{\circ} 38.404^{\prime} \mathrm{E}$; alt. 460 m; 10 May 2016; Pham CT and Nguyen TV leg.; collected on leaves next to a forest path; IEBR 4683.

Identification. Size small (male SVL $22.6 \mathrm{~mm}$ ); habitus moderately slender; head slightly longer than wide (HL $8.8 \mathrm{~mm}$, HW $7.9 \mathrm{~mm}$ ); snout slightly round, projecting beyond lower jaw (SL $3.5 \mathrm{~mm}$ ); snout length slightly greater than eye diameter (ED $3.2 \mathrm{~mm}$ ); canthus rostralis distinct, round; loreal region oblique, vertical slightly concave; interorbital distance wider than upper eyelid and internarial distance (IOD $2.7 \mathrm{~mm}$, IND $2.3 \mathrm{~mm}$, UEW $2.0 \mathrm{~mm}$ ); nostril lateral, without a lateral flap of skin, closer to the tip of snout than to eye (EN $2.2 \mathrm{~mm}$, NS $1.5 \mathrm{~mm}$ ); pupil diamond-shaped, horizontal; iris deep brick-red; pineal ocellus absent; spinules on upper eyelid absent; tympanum distinctly visible, round, about $56 \%$ of eye diameter (TYD $1.8 \mathrm{~mm}$ ); vomerine teeth absent; tongue cordiform, deeply notched posteriorly; vocal sac absent. Forelimbs: slender, short; tips of fingers enlarged into round discs with distinct circum-marginal grooves; fingers free of webbing; male with white nuptial pad on finger I. Length of tibia about six times greater than tibia width, shorter than the foot length; discs of toes smaller than those of fingers; webbing formula $11^{1 / 2}-1 \frac{1}{2}$ III$2 \frac{1}{2}$ III $2-3 I V 3-1 \frac{1}{2} \mathrm{~V}$; tibio-tarsal articulation reaching beyond tip of snout. Skin: dorsal surface of head and body 


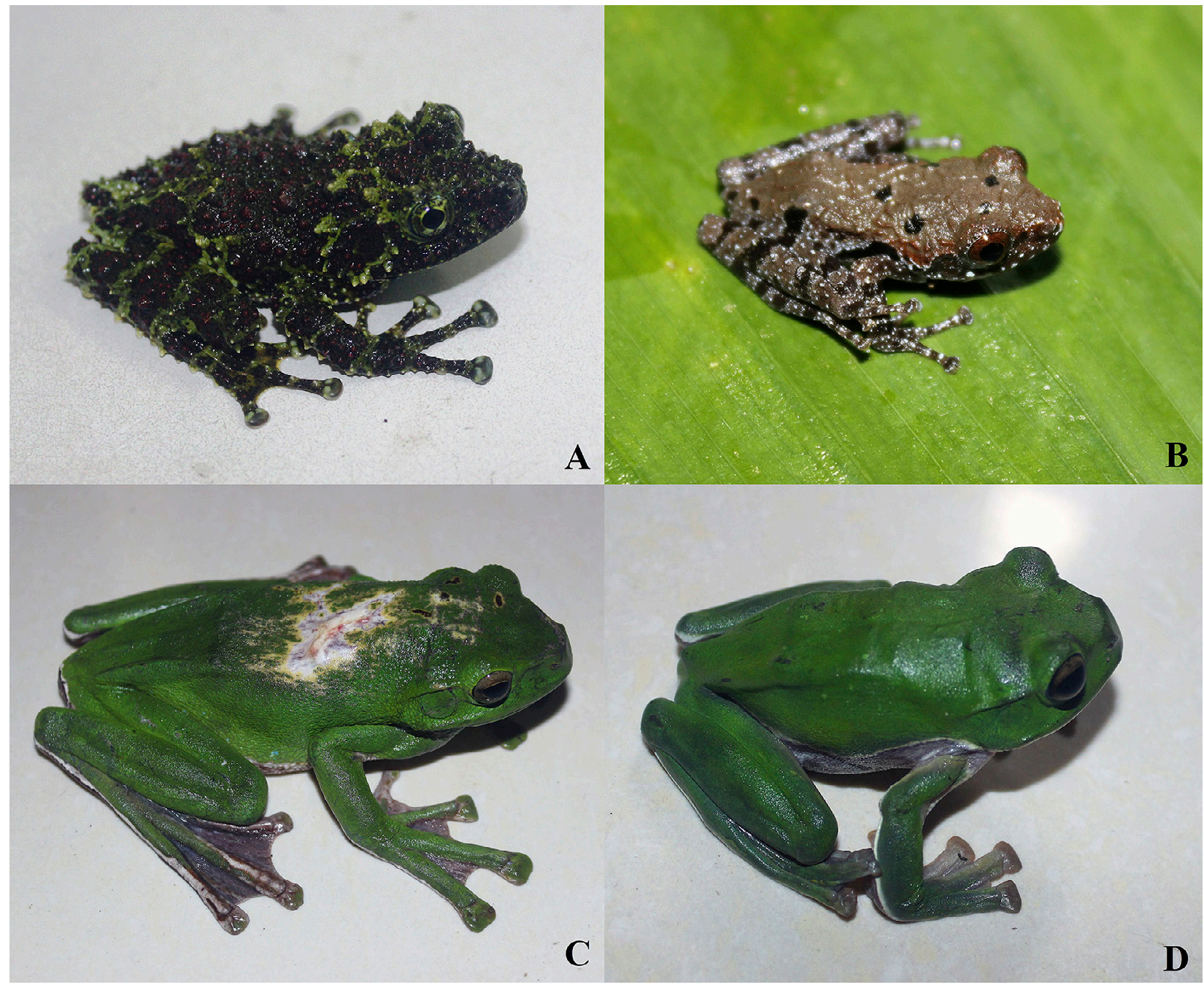

Figure 6. Rhacophoridae of Hai Ha forest, Quang Ninh Province, Vietnam. A. Theloderma corticale (IEBR 4682). B. Theloderma lateriticum (IEBR4683). C. Zhangixalus dennysi (IEBR 4685). D. Zhangixalus pachyproctus (IEBR 4688). Photographs C.T. Pham.

granular; posterior part of dorsum, flanks, dorsal surface and lateral sides of limbs with small calcified spicules; supratympanic and dorsolateral fold absent; throat, chest smooth; belly and ventral surface of thighs granular; dermal appendage at vent absent.

Colouration in life: dorsal surface of head and body deep brick-red or gray brown with some black blotches; upper lip and tympanum with small white spots; iris brickred; flank with bright white spots interspersed with black blotches; forelimb, dorsal surface of thigh, tibia and foot reddish brown with black bands; venter greyish brown with white spots (Bain et al. 2009; Hecht et al. 2013).

Distribution. In Vietnam, this species is currently known only from the type locality (Van Ban District, Lao Cai Province) (Frost 2020). This is the first record of T. lateriticum from Quang Ninh Province. Elsewhere, the species has been reported from Shiwandashan National Nature Reserve, southern Guangxi, China (Frost 2020).

\section{Zhangixalus dennysi (Blanford, 1881)}

Figure 6C

Materials examined. VIETNAM • 1 o, 2 \%; Quang Ninh Province, Hai Ha District, Quang Son Commune; $21^{\circ} 31.681^{\prime} \mathrm{N}, 107^{\circ} 38.582^{\prime} \mathrm{E}$; alt. $290 \mathrm{~m}$; 7 May 2016; Pham CT and Nguyen TV leg.; collected on tree branches near small streams, about $1.0-2.0 \mathrm{~m}$ above the ground; IEBR 4684-4686.

Identification. Size large (male SVL $85.2 \mathrm{~mm}$, females SVL 82.1-107.9 $\mathrm{mm}$ ); head slightly broader than long (HL 27.1-34.6 mm, HW 29.7-36 mm); nostril oval, closer to tip of snout than to eye (NS 5.1-6.2 mm, EN 7.1-8.1 $\mathrm{mm}$ ); tympanum round, smaller than eye diameter (TYD 5.3-7.1 mm, ED 7.1-8.1 mm); vomerine teeth present; tongue notched posteriorly; the male with vocal sac. Tips of fingers with enlarged discs, larger than those of toes,

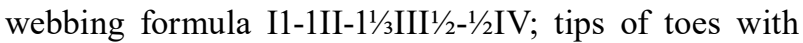
enlarged discs, toes fully webbed; tibio-tarsal articulation reaching between eye and tip of snout. Skin: dorsum and flanks smooth; belly and ventral surface of thighs granular; supratympanic fold distinct.

Coloration in life: dorsum green with whitish grey blotches; lower part of flanks and venter cream; chest green (Ziegler 2002; Fei et al. 2009, 2010).

Distribution. In Vietnam, this species has been reported from Cao Bang Province in the north, southward to Quang Binh Province (Pham et al. 2017a). This is the first 
record of Z. dennysi from Quang Ninh Province. Elsewhere, the species has been reported from China, Myanmar, and Laos (Nguyen et al. 2009; Frost 2020).

\section{Zhangixalus pachyproctus Yu, Hui, Hou, Wu, Rao \& Yang 2019 \\ Figure 6D}

Materials examined. VIETNAM • 2 o; Quang Ninh Province, Hai Ha District, Quang Son Commune; $21^{\circ} 31.633^{\prime} \mathrm{N}, 107^{\circ} 38.640^{\prime} \mathrm{E}$; alt. $234 \mathrm{~m}$; 6 May 2016; Pham CT and Nguyen TV leg.; collected on tree branches near rocky streams, about $1.5-2.5 \mathrm{~m}$ above the ground; IEBR 4687-4688.

Identification. Size large (females SVL 73.1-93.9 mm); head broader than long (HL 25.2-34.6 mm, HW 27.2$37.9 \mathrm{~mm}$ ); nostril oval, closer to tip of snout than to eye (NS 5.3-6.5 mm, EN 5.9-8.4 mm); tympanum distinct, round, smaller than eye diameter (TYD 4.8-6.0 $\mathrm{mm}$, ED $6.5-7.7 \mathrm{~mm}$ ); vomerine teeth present; tongue notched posteriorly. Fingers with webbing, webbing formula I1 $-1 / 2 \mathrm{II} 1 / 3-1 / 3 \mathrm{III} 1 / 3-1 / 2 \mathrm{IV}$; tips of fingers with enlarged discs; toes fully webbed, tips of toes with enlarged discs, smaller than those of fingers; tibio-tarsal articulation reaching between eye and tip of snout. Skin: dorsum smooth; belly, ventral surface of thighs, and lower part of flank ganular; supratympanic fold distinct.

Coloration in life: dorsal surface of head and body uniformly green; a narrow white stripe present along the flanks; venter cream (Yu et al. 2019).

Distribution. In Vietnam, this species has been reported from Dien Bien, Son La, Cao Bang, Bac Giang, Thanh Hoa, Nghe An and Quang Binh provinces (Pham et al. 2017a; Yu et al. 2019). This is the first record of Z. pachyproctus from Quang Ninh Province. Elsewhere, the species has been reported from Southern Yunnan, Thailand, and Laos (Yu et al. 2019; Frost 2020).

Remarks. Based on morphological and molecular evidences Yu et al. (2019) suggested that previous records of Rhacophorus maximus in Vietnam, Laos, and Thailand should be provisionally assigned to $Z$. pachyproctus. Zhangixalus pachyproctus can be distinguished from its sister species by the combination of the following characters: the protruding vent (vs not protruding in Z. smaragdinus); the shape of snout (more oblique in profile than that in $Z$. smaragdinus); interspace between vomerine teeth ridges norrow (broader in $Z$. smaragdi$n u s$ ); color pattern (large thick grey reticular mottles below the white stripe on flankvs fine in $Z$. smaragdinus) (Yu et al. 2019).

\section{Discussion}

In this study, 27 species of amphibians were recorded from the Hai Ha forest in Quang Ninh Province. We found the highest number of species (seven) belonging to family Dicroglossidae, followed by Ranidae and Rhacophoridae with six each. Ten species-Ingerophrynus galeatus, Leptobrachella minima, Megophrys maosonensis, Odorrana chloronota, Quasipaa acanthophora, Kurixalus cf. hainanus, Theloderma lateriticum, T. corticale, Zhangixalus dennysi, and Z. pachyproctus - were recorded for the first time from Quang Ninh Province. Among the reported species, Limnonectes quangninhensis and Quasipaa acanthophora are currently known only from Vietnam (Dubois and Ohler 2009; Pham et al. 2017b). The evergreen forest of Hai Ha District also harbors several threatened species: one species $(Q$. acanthophora) listed as Vulnerable in the IUCN Red List (2020) and two species (I. galeatus and T. corticale) listed as Endangered in the Red Data Book of Vietnam (Tran et al. 2007). Although the evergreen forest of Hai Ha District harbors a considerable number of endemic and threatened species, its biodiversity is currently threatened by expanding agriculture and illegal timber logging (Pham et al. 2017b). In addition, amphibians and reptiles are also collected by local people for food and pet trade. A new water snake species recently discovered in Hai Ha was tracked in the pet trade in Vietnam before its official discovery (Ziegler et al. 2019), revealing that capture events for the wild animal trade happen in this region, which also harbours rare, endemic and threatened taxa such as the Vietnamese Crocodile Lizard (Shinisaurus crocodilurus vietnamensis van Schingen, Le, Ngo, Pham, Ha, Nguyen \& Ziegler, 2016) (van Schingen et al. 2016a, 2016b). Additional surveys are required to obtain further data on the actual biodiversity of this forest. The establishment of a new protected area should be seriously considered in order to protect the remaining evergreen forests and their unique biodiversity in Quang Ninh Province.

\section{Acknowledgements}

We are grateful to the directorate of the Forest Protection Department of Quang Ninh Province for support of our field work and issuing relevant permits (no. 432/ TCL-BTTN on 13 April 2015 and no. 436/TCL-BTTN on 31 March 2016). We thank T.V. Nguyen (Ninh Binh) for their assistance in the field and AM Luong (Hanoi) for laboratory assistance. We thank T.A. Tran (Hanoi) for providing the map. For the fruitful cooperation within joint amphibian projects we cordially thank SV Nguyen (Hanoi), T. Pagel, and C. Landsberg (Cologne Zoo). This research was funded by the Vietnam Academy of Science and Technology (grant no. VAST04.09/19-20) to C.T. Pham.

\section{Authors' Contributions}

CTP and HNN collected materials in the field; CTP, QHD, and TQN wrote the manuscript; TQN, TTT, and $\mathrm{TZ}$ reviewed the manuscript. 


\section{References}

Bain RH, Nguyen TQ (2004a) Three new species of narrow-mouth frog (genus: Microhyla) from Indochina, with comments on $\mathrm{Mi}$ crohyla annamensis and Microhyla palmipes. Copeia 3: 507-524. https://doi.org/10.1643/CH-04-020R2

Bain RH, Nguyen TQ (2004b) Herpetofaunal diversity of Ha Giang Province in northeastern Vietnam, with description of two new species. American Museum Novitates 3453: 1-42. https://doi org/10.1206/0003-0082(2004)453<0001:hdohgp >2.0.co;2

Bain RH, Nguyen TQ, Doan KV (2009) A new species of the genus Theloderma Tschudi, 1838 (Anura: Rhacophoridae) from northwestern Vietnam. Zootaxa 2191: 58-68. https://doi.org/10.11646/zoo taxa.2191.1.3

Bain RH, Lathrop A, Murphy RW, Orlov NL, Ho CT (2003) Cryptic species of a cascade frog from Southeast Asia: taxonomic revisions and descriptions of six new species. American Museum Novitates 3417: 1-60.

Bourret R (1942) Les batraciens de l'Indochine. Gouvernement Général de l'Indochine, Hanoi, $517 \mathrm{pp}$

David P, Nguyen TQ, Nguyen TT, Jiang K, Chen TB, Teynié A, Ziegler $\mathrm{T}$ (2012) A new species of the genus Oligodon Fitzinger, 1826 (Squamata: Colubridae) from northern Vietnam. southern China and central Laos. Zootaxa 3498: 45-62. https://doi.org/10.11646/ zootaxa.3498.1.3

Dubois A, Ohler A (2009) A new species of the genus Quasipaa (Anura, Ranidae, Dicroglossinae) from northern Vietnam. Alytes 27: 49-61.

Fei L, Hu S, Ye C, Huang Y (2009) Fauna Sinica. Amphibia. Volume 3. Anura. Science Press, Beijing, 887 pp.

Fei L, Ye C, Jiang J (2010) Colored atlas of Chinese amphibians. Sichuan Publishing House of Science and Technology, Sichuan, 519 pp.

Frost DR (2020) Amphibian species of the world: an online reference. Version 6.0. American Museum of Natural History, NewYork, USA. http://research.amnh.org/herpetology/amphibia. Accessed on: 2020-2-6.

Glaw F, Vences M (2007) A field guide to the amphibians and reptiles of Madagascar. Third edition. FroschVerlag, Cologne, $496 \mathrm{pp}$.

Hecht V, Pham CT, Nguyen TT, Nguyen TQ, Bonkowski M, Ziegler $\mathrm{T}$ (2013) First report on the herpetofauna of Tay Yen Tu Nature Reserve, northeastern Vietnam. Biodiversity Journal 4: 507-552.

Hou M, Yu G, Chen H, Liao C, Zhang L, Chen J, Li P, Orlov NL (2017) The taxonomic status and distribution range of six Theloderma species (Anura: Rhacophoridae) with a new record in China. Russian Journal of Herpetology 24: 99-127.

Inger, RF, Stuart BL (2010) Systematics of Limnonectes (Taylorana) Dubois. Current Herpetology 29: 51-68. https://doi.org/10. 3105/018.029.0201

Inger RF, Orlov NL, Darevsky I (1999) Frogs of Vietnam: a report on new collection. Fieldiana: Zoology (New Series) 92: 1-46. https:// doi.org/10.5962/bhl.title.3478

IUCN (2020) The IUCN Red List of threatened species. Version 2020.1. http://www.iucnredlist.org. Accessed on: 2020-2-6.

Janssen HY, Pham CT, Ngo HT, Le MD, Nguyen TQ, Ziegler T (2019) A new species of Lycodon Boie, 1826 (Serpentes, Colubridae) from northern Vietnam. ZooKeys 875: 1-29. https://doi.org/ 10.3897/zookeys.875.35933

Kuraishi N, Matsui M, Hamidy A, Belabut MD, Ahmad N, Panha S, Sudin A, Yong SH, Jiang J, Ota H, Ho TT, Nishikawa K (2013) Phylogenetic and taxonomic relationships of the Polypedates leucomystax complex (Amphibia). Zoologica Scripta 42: 54-70. https://doi.org/10.1111/j.1463-6409.2012.00562

Luu VQ, Nguyen TQ, Pham CT, Dang KN, Vu TN, Miskovic S, Bonkowski M, Ziegler T (2013) No end in sight? Further new records of amphibians and reptiles from PhongNha-Ke Bang National Park, Quang Binh Province, Vietnam. Biodiversity Journal 4 (2): $285-300$
McLeod DS, Kurlbaum S, Hoang NV (2015) More of the same: a diminutive new species of the Limnonectes kuhlii complex from northern Vietnam (Anura: Dicroglossidae). Zootaxa 3947: 201214. https://doi.org/10.11646/zootaxa.3947.2.4

Nguyen TQ, Wang YY, Yang YH, Lehmann T, Le MD, Ziegler T, Bonkowski M (2013) A new species of the Gekko japonicus group (Squamata: Sauria: Gekkonidae) from the border region between China and Vietnam. Zootaxa 3652: 501-518. https://doi. org/10.11646/zootaxa.3652.5.1

Nguyen SV, Ho CT, Nguyen TQ (2009) Herpetofauna of Vietnam. Edition Chimaira, Frankfurt am Main, 768 pp.

Ohler A (2003) Revision of the genus Ophryophryne Boulenger, 1903 (Megophryidae) with description of two new species. Alytes 21: 23-42.

Ohler A, Wollenberg KC, Grosjean S, Hendrix R, Vences M, Ziegler T, Dubois A (2011) Sorting out Lalos: description of new species and additional taxonomic data on megophryid frogs from northern Indochina (genus Leptolalax, Megophryidae, Anura). Zootaxa 3147: 1-83. http://doi.org/10.11646/zootaxa.3147.1.1

Orlov NL, Dutta S, Ghate H, Kent Y (2006) New species of Theloderma from Kon Tum province (Vietnam) and Nagaland state (India) (Anura: Rhacophoridae). Russian Journal of Herpetology 13: 135-154. https://doi.org/10.30906/1026-2296-2006-13-2-135-154

Pham CT, An HT, Herbst S, Bonkowski M, Ziegler T, Nguyen TQ (2017a) First report on the amphibian fauna of Ha Lang karst forest, Cao Bang Province, Vietnam. Bonn Zoological Bulletin 66 (1): 37-53.

Pham CT, Le MD, Nguyen TT, Ziegler T, Wu ZJ, Nguyen TQ (2017b) A new species of Limnonectes (Amphibia: Anura: Dicroglossidae) from Vietnam. Zootaxa 4269: 545-558. https://doi.org/10.11646/ zootaxa.4269.4.8

Pham CT, Le MD, Ngo HT, Ziegler T, Nguyen TQ (2018) A new species of Limnonectes (Amphibia: Anura: Dicroglossidae) from Vietnam. Zootaxa 4508: 115-130. https://doi.org/10.11646/zoo taxa.4508.1.7

Pham CT, Le MD, Hoang CV, Pham AV, Ziegler T, Nguyen TQ (2020) First records of Bufo luchunnicus (Yang \& Rao, 2008) and Amolops wenshanensis Yuan, Jin, Li, Stuart \& Wu, 2018 (Anura: Bufonidae, Ranidae) From Vietnam. Russian Journal of Herpetology 27 (2): 81-86. https://doi.org/10.30906/1026-2296-2020-27-2-81-86

Pham CT, Nguyen TQ, Bernades M, Nguyen TT, Ziegler T (2016) First records of Bufo gargarizans Cantor, 1842 and Odorrana lipuensis Mo, Chen, Wu, Zhang \& Zhou, 2015 (Anura: Bufonidae, Ranidae) from Vietnam. Russian Journal of Herpetology 22: 103-107. https://doi.org/10.30906/1026-2296-2016-23-2-103-107

Pham CT, Phan TQ, Do DT, Nguyen TQ (2019) New provincial records of genus Limnonectes (Amphibia: Anura: Dicroglossidae) from Vietnam. Journal of Biology 41 (2se1\&2se2): 169-176.

Taylor EH (1962) The amphibian fauna of Thailand. University of Kansas Science Bulletin 63: 265-599.

Tran K, Ho CT, Nguyen SV, Pham T (2007) Reptiles and Amphibians. in: Dang TN, Tran K, Dang HH, Nguyen C, Nguyen TN, Nguyen YH, Dang DT (Eds) Vietnam Red Data Book, part 1. Animals. Publishing House for Science and Technology, Hanoi, 219-276 $+8 \mathrm{pls}$.

van Schingen M, Ha QQ, Pham CT, Le TQ, Nguyen TQ, Bonkowski M, Ziegler T (2016a) Discovery of a new crocodile lizard population in Vietnam: population trends, future prognoses and identification of key habitats for conservation. Revue Suisse de Zoologie 132 (2): 241-251. https://doi.org/10.5281/zenodo. 155297

van Schingen M, Le MD, Ngo HT, Pham CT, Ha QQ, Nguyen TQ, Ziegler T (2016b) Is there more than one crocodile lizard? An integrative taxonomic approach reveals Vietnamese and Chinese Shinisaurus crocodilurus represent separate conservation and taxonomic units. Der Zoologische Garten 85 (2): 240-260. https:// doi.org/10.1016/j.zoolgart.2016.06.001

Zhao EM, Wang LJ, Shi HT, Wu GF, Zhao H (2005) Chinese 
rhacophorid frogs and description of a new species of Rhacophorus. Sichuan Journal of Zoology 24 (3): 297-300.

Ziegler T (2002) Die Amphibien und Reptilien eines Tieflandfeuchtwald-Schutzgebiets in Vietnam. Natur \& Tier Verlag, Münster, 342pp

Ziegler T, Ohler A, Vu TN, Le QK, Nguyen TX, Dinh TH, Bui TN (2006) Review of the amphibian and reptile diversity of Phong Nha-Ke Bang Nationnal Park and adjacent areas, central Truong Son, Vietnam. Proceeding of the 13th Congress of the Societas Europaea Herpetologica: 247-262.

Ziegler T, Pham, CT, Nguyen TV, Nguyen TQ, Wang J, Wang YY, Stuart BL, Le MD (2019) A new species of Opisthotropis from northern Vietnam previously misidentified as the Yellow-spotted Mountain Stream Keelback O. maculosa Stuart \& Chuyankern, 2007 (Squamata: Natricidae). Zootaxa 4613 (3): 579-586. http:// doi.org/10.11646/zootaxa.4613.3.9
Ye C, Fei L, Xie F, Jiang J (2007) A new Ranidae species from ChinaLimnonectes bannaensis (Ranidae: Anura). Zoological Research/ Dōngwùxué yánjiū 28: 545-550.

Yu G, Rao D, Matsui M, Yang J (2017) Coalescent-based delimitation outperforms distance-based methods for delineating less divergent species: the case of Kurixalus odontotarsus species group. Scientific Reports 7 (16124): 1-13. https://doi.org/10.1038/s41598017-16309-1

Yu G, Hui H, Hou M, Wu Z, Rao D, Yang J (2019) A new species of Zhangixalus (Anura: Rhacophoridae), previously confused with Zhangixalus smaragdinus (Blyth, 1852). Zootaxa 4711: 275-292. http://doi.org/10.11646/zootaxa.4711.2.3

Yuan Z, Jin J, Li J, Stuart BL, Wu J (2018) A new species of cascade frog (Amphibia: Ranidae) in the Amolops monticola group from China. Zootaxa 4415: 498-512. http://oi.org/10.11646/zoo taxa.4415.3.5 